\title{
On the origin, evolution, and nature of programmed cell death: a timeline of four billion years
}

\author{
JC Ameisen*,1 \\ 1 EMI-U 9922 INSERM/Université Paris 7, IFR 02, Hôpital Bichat-Claude \\ Bernard, AP-HP, 46 rue Henri Huchard, 75877 Paris cedex 18, France \\ * Corresponding author: JC Ameisen. Tel: +331402586 01; \\ Fax: +33 1402586 02; E-mail: ants@club-internet.fr
}

Received 25.6.01; revised 31.8.01; accepted 31.8.01

Edited by G Melino

\begin{abstract}
Programmed cell death is a genetically regulated process of cell suicide that is central to the development, homeostasis and integrity of multicellular organisms. Conversely, the dysregulation of mechanisms controlling cell suicide plays a role in the pathogenesis of a wide range of diseases. While great progress has been achieved in the unveiling of the molecular mechanisms of programmed cell death, a new level of complexity, with important therapeutic implications, has begun to emerge, suggesting (i) that several different selfdestruction pathways may exist and operate in parallel in our cells, and (ii) that molecular effectors of cell suicide may also perform other functions unrelated to cell death induction and crucial to cell survival. In this review, I will argue that this new level of complexity, implying that there may be no such thing as a 'bona fide' genetic death program in our cells, might be better understood when considered in an evolutionary context. And a new view of the regulated cell suicide pathways emerges when one attempts to ask the question of when and how they may have become selected during evolution, at the level of ancestral single-celled organisms.

Cell Death and Differentiation (2002) 9, 367-393. DOI: 10.1038/ sj/cdd/4400950
\end{abstract}

Keywords: programmed cell death; apoptosis; evolution; singlecelled eukaryotes; bacteria; symbiosis

Abbreviations: APAF-1, apoptotic protease-activating factor 1; AIF, apoptosis inducing factor; TNFR, tumor necrosis factor receptor; DED, death-effector domains; CARD, caspase activation and recruitment domains; IAPs, inhibitor of apoptosis proteins

\section{On programmed cell death in multicellular organisms}

Initial questions about the possible existence, mechanisms, and role of physiological cell death emerged during the second half of the 19th century, from the study of animal development, ${ }^{1,2}$ but it is only during the second half of the 20 th century that a series of conceptual and experimental advances progressively led to the idea that cells from multicellular animals may have the capacity to activate a program of self-destruction, and that this self-destruction program may be regulated by signals provided by other cells. ${ }^{1-16}$ The identification of a genetic regulation of physiological cell death, of the orderly features of its most frequent phenotype, apoptosis, and of its central role, not only in development, but also in adult tissue homeostasis, has led to the acceptance of the idea that all cells from all multicellular animals may be intrinsically programmed to self-destruct, and that cell survival continuously depends on the repression of this self-destruction program by other cells, in other words that cells may survive only as long as they are signaled by other cells to suppress the induction of a 'default' pathway leading to cell suicide..$^{7,16-20}$ Hence, in a counterintuitive manner, a positive event-life-seems to proceed through the continuous repression of a negative event-self-destruction.

The coupling of the fate of each cell to the nature of the interactions it can establish with other cells has led to the concept of 'social control' of cell survival and cell death, allowing a stringent regulation of cell numbers, of their geographic localization, and a constant adjustment of the different cell types that constitute our organs and tissues. ${ }^{17}$ This very frailty, this permanent reprieve and the interdependence they generate between our cells, are one of the bases of our perennity and our plasticity, allowing our bodies to build themselves, to constantly reconstruct, and to adapt to ever changing environments.

But the permanent coupling of each cell fate to the nature of the interactions it can establish with the collectivity to which it belongs, represents only one dimension of the 'social control' of cell survival and cell death. At another level, each individual cell may be considered as a complex entity, a 'society' by itself, a mingling of heterogeneous organelles and components that behaves as a whole. And self-destruction can occur not only as a response to signals originating from the outside environment of the cell, but also from its inside environment. Accordingly, genetic damage causes the activation of the p53 protein family, that induces either DNA repair and cell cycle arrest, or programmed cell death, a radical and extreme means preventing the emergence of genetic heterogeneity, and the progression towards cancer. ${ }^{21}$ Similarly, alterations in endoplasmic reticulum integrity, induced, for example, by abnormal protein folding, ${ }^{22}$ or alterations in mitochondrial activity, such as respiratory chain dysfunction ${ }^{23}$ can induce signaling leading to programmed cell death. Thus, cell suicide plays an essential role in the maintenance of the genetic identity and the integrity of the body, by inducing the rapid elimination of altered cells. 
Programmed cell death plays a central role in development, $^{3,5,10,16,20,24,25}$ participating in particular in morphogenesis (the sculpting of the form of embryos), in sexual differentiation, and in the epigenetic self-organization processes that allow the emergence of the two most complex regulatory organs of our body, the immune system and the nervous system. ${ }^{26-29}$ Programmed cell death is also crucial in the adult, by allowing tissue homeostasis, elimination of damaged or abnormal cells, and defense against infections. ${ }^{17,20,25,30-34}$ It may also play an important but poorly explored physiological role in metabolism, by allowing energy recycling through the ingestion of dying cells by neighboring cells. Conversely, programmed cell death dysregulation has been proposed to participate in the pathogenesis of several diseases, ranging from cancer and autoimmunity to infectious diseases and neurodegenerative disorders, ${ }^{9,14,29,35-45}$ leading to the emergence of new concepts of therapeutic intervention, aimed at the selective modulation of the mechanisms involved in the regulation of cell death and cell survival. ${ }^{29,35,37,40,46-48}$ Finally, programmed cell death may also participate in the physiologically regulated process of aging. ${ }^{9,49}$

\section{Programmed cell death, cell suicide and apoptosis: on the implications of terminology}

These cell death processes have been successively named 'chromatolysis'; 'pyknosis'; 'karyolysis'; 'karyorhexis'; 'shrinkage necrosis'; 'programmed cell death', 'cell suicide', 'selfdestruction' and 'apoptosis'. 1,2,4,7,50-52 The terms 'programmed cell death', 'cell suicide' and 'apoptosis' have each played a major role in expressing crucial conceptual advances concerning cell death and in promoting interest for the field, but it should also be noted that none of these terms are synonymous, that each one carries its own metaphors and philosophical implications, ${ }^{53,54}$ and hence some degree of ambiguity. Accordingly, while "it is not possible to do the work of science without using a language that is filled with metaphors", "the price of metaphor is eternal vigilance" (quoted $\mathrm{in}^{55}$ ).

Etymologically, the term 'program' means 'pre-written'. Therefore, the very concept of program, in biology, is ambiguous, suggesting a framework of design and finality, and favoring a confusion between the existence of prewritten genetic information and the multiple ways they can be used by the cells and the body. Accordingly, it is not the individual fate of each cell, its survival or its death, that is programmed (pre-written), but the capacity of each cell to induce or repress its self-destruction, depending on its present and past interactions with the other cells that constitute the body, and on the integrity of its internal components. The concept of 'cell suicide' or 'self-destruction' also provides some level of ambiguity, not only because of its obvious anthropomorphic reference, but also because it favors a confusion between the act of initiating selfdismantling (that the cell indeed performs by activating an intrinsic cell death machinery) and both the 'decision' to kill itself and the implementation of the death process (that depends on the nature of interactions between the cell and the body, rather than on the cell itself). Finally, the term 'apoptosis' (etymologically, the 'fall', as that of leaves in autumn), while implicitly perceived as describing the death process itself, describes actually a phenotype: the stereotyped series of modifications usually associated with programmed cell death. These various and spectacular changes involve cell shrinkage, plasma membrane blebbing with partial maintenance of impermeability, mitochondria outer membrane permeabilization, nuclear chromatin condensation and fragmentation, genomic DNA fragmentation, cytoskeletal modifications, and segmentation of the cell into apoptotic bodies. They also involve the expression of various death signaling molecules, such as phosphatidylserine, on the outer leaflet of the plasma membrane, that allows neighboring cells to rapidly ingest the dying cell, usually long before it has completed self-dismantling, ${ }^{56}$ preventing any reversal of the self-destruction process and leading to the swift elimination of the apoptotic cells. Several of these features of apoptosis contribute to the fact that programmed cell death, in contrast with passive and chaotic necrotic death (that involves cell swelling, plasma membrane rupture, and cell content spilling), usually induces no lesions in the organ and tissue in which it occurs. But while apoptosis is a quiet form of cell death, it is not a silent one. Because apoptosis is an active process, the dying cell can emit signals that will modify the behavior of neighboring cells, including the neighboring cells that are ingesting them. ${ }^{56,57}$ Finally, although apoptosis is the most typical and frequent phenotype of self-destruction, it is not the sole one. 1,2,15,52,58-60 For this reason, the term 'apoptosis' should not be considered as a synonym of the terms 'programmed cell death', 'cell suicide' or 'self-destruction'. And the common use of these terms as identical has favored a confusion between the nature of the effectors that may be responsible for the execution of cell death, and the effectors that are responsible for the execution of the apoptotic phenotype, while not being obligatorily the cause of death. ${ }^{61,62}$

\section{On the conserved nature of programmed cell death in multicellular animals}

Programmed cell death has been found to operate in all multicellular animals studied so far, including cnidaria, nematodes, insects, amphibians, birds and mammals. ${ }^{16,18,20,24,25,63,64}$ The evolutionary conservation of programmed cell death in the animal kingdom does not only involve its existence and role, but extends to some central aspects of its genetic control, and to important aspects of its most frequent phenotype, apoptosis. $5,16,18,20,24,25,63,64$ In all cases that have been studied to date, programmed cell death is regulated by signals provided by other cells, either in the form of cell-lineage information, of soluble mediators, or of cell-to-cell contacts. Programmed cell death induction may depend essentially on cell-lineage information, such as in the nematode Caenorhabditis elegans, on the activation of gene transcription, such as in the fruitfly Drosophila melanogaster, or, in a more stochastic way, on a combination of cell-lineage information, intercellular signaling, transcription factor activation and cytoplasmic second messengers, such as in mammals. $^{20}$ 
The first evidence for the existence of genetic information specific for the control of cell death was provided by pioneering experiments on the nematode Caenorhabditis elegans, ${ }^{12,16,65-69}$ a metazoan whose phylogenic divergence predates ours by several hundred million years and whose body is constituted of less than a thousand somatic cells. During the development of Caenorhabditis elegans, a little less than $15 \%$ of the somatic cells die with a phenotype similar to apoptosis, and are rapidly ingested by neighboring cells. The investigation of genetic mutants revealed that the survival or death of most, if not all, cells during development depends on the presence, and expression, of only four genes, ced-3, ced-4, ced-9, and egl-1. ${ }^{19,20,69}$ In addition to these four gene products involved in the control of selfdestruction and survival, there are at least seven additional gene products that allow the rapid ingestion of the dying cells by the neighboring cells, ${ }^{56,69}$

Ced-3, the protein most downstream in the induction of cell death, seems to play the role of an executioner. It is an aspartate-directed cystein proteinase (a caspase) that, like most proteases, is synthesized as an inactive pro-enzyme precursor, and requires to be cleaved to become active. Ced-4 is an adaptor protein that, by oligomerizing and binding the Ced-3 pro-enzyme, induces Ced-3 autocatalytic cleavage and activation. Ced-9 is a repressor of cell death that, by binding Ced-4, prevents it from activating Ced-3. Finally, Egl-1 is an antagonist of Ced-9, that by binding Ced- 9 prevents its protective effect, releasing Ced- 4 from Ced-9, and allowing Ced-4 to activate Ced-3 and to trigger self-destruction. These findings provided a new paradigm: a simple genetic module suffices to control the fate of all somatic cells in response to the various cell-lineage and cell-type specific signals involved in cell differentiation and embryonic development. At the same time, these findings also illustrated the ambiguity intrinsic to the concept of a 'death program'. Indeed, Ced-3 is an executioner of cell death, but only if Ced-4 is present and available; Ced-4 is an activator of the executioner, but only if Ced-9 is lacking or not available; and Ced-9 is a repressor of cell death, but only if Egl-1 is lacking, or not available. In other words, the completion of the 'death program' will depend, in each cell, on the interactions between each of these four proteins, that depend, at least in part, on their respective expression level, regulated by cell signaling during development. An additional level of ambiguity and complexity concerning the 'death program' has been suggested by the very recent finding that the activation of the Ced-3 executioner may not obligatorily represent a 'point of no return' beyond which cells are condemned to die, and that an unexpected form of social control may be involved in the implementation of cell death. Indeed, while Ced-3 activation seems required for the initiation of self-destruction, the execution of cell death in at least one cell type (and in several additional cell types in Ced-3-partial-loss-of-function mutants) also requires the expression, in the neighboring surviving cells, of the proteins involved in the ingestion of dying cells. ${ }^{70,71}$

During the last nine years, homologues of genes involved in the regulation of programmed cell death in Caenorhabditis elegans have been identified in sponge, ${ }^{72}$ in Hydra vulgaris, $^{64}$ in the fruitfly Drosophila melanogaster, ${ }^{20}$ in zebrafish $^{73}$ in mice and in humans. ${ }^{74,75}$ As frequently occurs during evolution, however, this striking conservation in both sequences ${ }^{20,25,64,69}$ and functional properties ${ }^{76}$ has been associated with a great level of diversification. ${ }^{19,20,25}$

In humans and mice, around twenty gene products that are homologues of the cell death repressor Ced-9 and its antagonist Egl-1 (the Bcl-2 family) have been identified, as well as more than ten homologues of the executioner Ced-3 (the caspase family) and at least one homologue of Ced-4 (Apaf-1, or apoptotic protease-activating factor 1). The death repressors $\left(\mathrm{Bcl}-2 / \mathrm{Bcl}-\mathrm{X}_{\mathrm{L}} \ldots\right)$ ) and their antagonists (Bax/ Bak/Bid ...) share the capacity to homodimerize and to neutralize each others through heterodimerization, and, for some of them, to insert through a carboxyterminal hydrophobic transmembrane domain into the outer membrane of intracellular organelles such as the nucleus, endoplasmic reticulum and mitochondria. While there are alternative views, ${ }^{77}$ it is generally believed that it is through their control of mitochondrial outer membrane permeability that the $\mathrm{Bcl}-2 / \mathrm{Bax}$ family members exert an important part of their antagonistic effect on cell death and survival, by repressing $(\mathrm{Bcl}-2)$ or inducing $(\mathrm{Bax})$ the release into the cytosol of mitochondrial intermembrane space proteins that will favor the induction of cell death. ${ }^{19,20,78-82}$ Some of these intermembrane space proteins, such as cytochrome $c$, Smac/Diablo, and Omi/HtrA2 will favor caspase activation, ${ }^{20,80,82,83}$ while others, such as AIF (apoptosis inducing factor), ${ }^{84}$ or endonuclease $\mathrm{G}^{85}$ may favor the induction of caspase-independent executionary pathways. Some of the caspases, termed effector or executionary caspases, such as caspase 3, 6 and 7, are involved in cell death through their cleavage of numerous nuclear and cytoplasmic proteins, thereby inducing several of the typical features of apoptosis. $^{19,86}$ The activation of these effector caspases requires their prior cleavage by other upstream caspases, called initiator caspase, such as caspase 8 and 9, that are autocatalytically cleaved and activated through recruitment by adaptor proteins that share death-effector domains (DED) or caspase activation and recruitment domains (CARD) with these initiator caspases. ${ }^{19,45,80,87}$ The activation of initiator caspases can be directly coupled to cell surface receptor signaling, such as caspase 8 activation induced by the recruitment of the FADD adaptor protein, consecutive to the engagement of 'death' receptors of the CD95/tumor necrosis factor receptor (TNFR) family by their ligands. Other initiator caspases, such as caspase 9, are activated downstream of the mitochondria outer membrane permeabilization induced by members of the Bax family in response to various proapoptotic stimuli, through the release of cytochrome $c$ that activates the Apaf-1 adaptor protein. But these multiple pathways of activation, that can amplify each other, can also be repressed at the downstream common level of the effector caspases, for example by IAPs (inhibitors of apoptosis proteins) that block the activity of already processed caspases. ${ }^{88}$ And the IAPs themselves can be inhibited by the Smac/Diablo protein, that can be released by mitochondria. ${ }^{20,88}$ Finally, a series of knock-out experiments in mouse, involving the deletion of genes encoding either members of the Bcl-2/Bax family, the Apaf-1 and FADD adaptor proteins, members of the caspase family, or, 
more recently, cytochrome $c^{89}$ or $\mathrm{AIF}^{90}$ have indicated that each of these proteins controls some, but not all, suicide pathways, in some, but not all, cell types. Thus, in contrast to the simple paradigm of Caenorhabditis elegans, in mammalian cells, programmed cell death can proceed along multiple intracellular molecular pathways, and the pathways followed will not be the same in different cell types, in response to a given death signal, nor in the same cell type, in response to different death signals. In some instances, the molecular pathway leading to self-destruction will even be different in a given cell type, in response to the same death signal, depending on the particular differentiation stage of the cell. And the extent of the complexity of the molecular control of cell survival and cell death cannot be fully appreciated if one does not take into account the various epigenetic mechanisms such as alternative splicing and post-translational modifications (phosphorylation, dephosphorylation, or proteolytic cleavage) that can transform the product of a given gene into either a pro-apoptotic or an anti-apoptotic protein. ${ }^{20,29,78,91}$

\section{On phylogenic variations of programmed cell death in multicellular animals}

So far, the molecular machinery involved in programmed cell death regulation has been investigated in only four phylogenic branches of metazoans, the cnidaria, nematodes, insects, and mammals, and in each of these branches, in only one (Hydra vulgaris, Caenorhabditis elegans, Drosophila melanogaster), or two (mouse and human) species. Some homologues of the gene products involved in the control and execution of programmed cell death have been found to be present in these five species. ${ }^{20,64,92}$ They include (i) proapoptotic members of the Bcl-2 family, i.e. Egl-1 in $C$. elegans, dBok in D. melanogaster, and the Bax/Bak/Bid family in humans and mice; (ii) the apoptotic adenosine triphosphatase (AP-ATPase)-related family of caspase adaptor proteins with CARD domains, i.e. Ced-4 in $C$. elegans, Dark in D. melanogaster, and Apaf-1 in humans and mice; and finally (iii) the caspases, i.e. Ced-3 and two additional caspases that seem dispensable for the induction of developmental cell death in $C$. elegans, two caspases that seem involved in $H$. vulgaris cell death, ${ }^{64}$ at least five caspases involved in cell death in $D$. melanogaster, and at least ten caspases involved in cell death in humans and mice. But besides this conserved core of homologues, other gene products that play a crucial role in the induction or repression of programmed cell death seem to be present in some, but not all of these species. ${ }^{20,92}$ For example, homologues of the anti-apoptotic members of the Ced-9/ $\mathrm{Bcl}-2$ family are present in $C$. elegans and mammals, but have not yet been identified in Drosophila and Hydra. Homologues of the Egl-1/Bid pro-apoptotic BH3-domainonly, that lack the carboxyterminal hydrophobic transmembrane domain required for insertion in the mitochondrial outermembrane, are present in C. elegans and mammals, while homologues of the Bax/Bak pro-apoptotic proteins, that can insert in mitochondria outermembrane are present in Drosophila and mammals, but not in C. elegans. ${ }^{20}$ Homologues of the anti-apoptotic BIR (baculoviral IAP repeat)- domain IAPs with caspase inhibitory functions are present in the fruitfly and the mammals, but not in $C$. elegans, in which the survivin homologue BIR-1 protein appears involved in the control of cell cycle but not of cell death. ${ }^{93}$ And while functional inhibitors of IAPs are present in both the fruitfly (Reaper, Hid and Grim) and mammals (Smac/Diablo), ${ }^{20}$ they share no sequence homologies, except for the aminoterminal residues allowing their interactions with IAPs, suggesting that they acquired their functions through a process of convergent evolution.

Finally, although caspases are present in all above mentioned animal species, the requirement for caspase activity in the execution of programmed cell death seems not to be the same in nematodes, insects, and mammals. In mammalian cells, while caspase activity is important for the induction of several typical features of the apoptotic phenotype including full nuclear chromatin condensation and fragmentation, and oligonucleosomal DNA fragmentation, ${ }^{19,86}$ the activation of caspases (at least of those that have been identified and can be inhibited) appears dispensable in several instances for the induction and execution of programmed cell death. ${ }^{59,84,94-100}$ In contrast, the requirement for caspase activity appears crucial to the induction and execution of programmed cell death in $C$. elegans and $D$. melanogaster. ${ }^{19,20,69}$ While a release of mitochondrial intermembrane space proteins has been reported to occur during $D$. melanogaster cell death, ${ }^{20}$ and a role for the homologue of the mitochondrial endonuclease $G$ has been very recently suggested in $C$. elegans apoptosis, ${ }^{101}$ these effectors seem to be involved in the amplification of caspase-dependent death, rather than to substitute for caspases in the execution of cell death in these species.

Together, these findings suggest that the recruitment of caspases and mitochondrial effectors to the cell death machinery may have been subjected not only to increased diversification and complexity, but also to phylogenic variation during the evolution of metazoans. They also suggest that the caspase cystein proteinases may have represented the initial, ancestral core of executioners that allowed the emergence of programmed cell death, prior to the recruitment of mitochondria as essential effectors of the cell death machinery. The problem with such implications, however, is that they are based on a view that equates the phylogeny of programmed cell death with that of the multicellular animals, and do not take into account the fact that these are not the sole multicellular organisms endowed with the capacity to self-destruct.

\section{On programmed cell death in plants}

While the conservation of programmed cell death in species of multicellular animals that diverged over several hundred million years ago has led to the idea that genetic programs of physiologic cell suicide have played an ancient and central role in the development, functioning and survival of multicellular animals, ${ }^{16,17,20,24,33,63,102}$ the question of the possible existence and role of programmed cell death in multicellular plants has long remained neglected.

Programmed cell death, however, also occurs in plants. Cell death is important in plant development, is involved in 
the generation of the vascular system, the xylem and the phloem, and also participates in the senescence of leaves and flowers and in the formation of bark. ${ }^{103-106}$ But the best studied forms of genetically regulated programmed cell death in plants is the 'hypersensitivity response' that plays an important role in plant defenses against infectious pathogens ${ }^{103-107}$ and shares some phenotypic features with apoptosis. ${ }^{108}$ The 'hypersensitivity response' is a process of self-destruction that occurs in the infected cells and in the neighboring cells in response to the presence of a micro-organism, and is genetically regulated at the level of the $R$ gene family, related to the Toll receptor family in Drosophila, and to the Toll-like receptor family in mammals, that respond to conserved microbial molecular patterns. The 'hypersensitivity response' has been reported to be associated with cystein proteinase activity, and to be inhibited by the expression of endogenous cystein proteinase inhibitors, such as cystatin. ${ }^{109}$ While peptides that inhibit mammalian caspase activity have been shown to also inhibit plant cell death induction during the 'hypersensitivity response', 110 no caspase homologue containing a caspasespecific catalytic cleavage site has yet been identified so far in plants. Recently, however, genes encoding caspase-like proteins, the metacaspases, that are not present in animals and appear to belong to an ancestral caspase/paracaspase/ metacaspase superfamily, have been identified in plants. ${ }^{111}$ Interestingly, a plant metacaspase shares a domain with a protein involved in the hypersensitivity response (Isd-1), but the potential role of metacaspases in programmed cell death remains unknown. An AP-ATPase-like protein with a Tir (Toll-interleukin-1 receptor) domain is involved in the hypersensitivity response, but its potential role in programmed cell death has not yet been determined. ${ }^{92}$ Also of interest, programmed cell death in plants has been reported to be associated with mitochondrial release of cytochrome $c$ into the cytosol, ${ }^{112}$ suggesting a potential involvement of mitochondria permeabilization in the death pathway. Finally, while the mammalian anti-apoptotic Bcl-XL protein and its $c$. elegans Ced- 9 homologue have been shown to inhibit plant cell death during the "hypersensitivity response', ${ }^{113}$ and the mammalian pro-apoptotic Bax protein to induce plant cell death, ${ }^{114}$ no homologues of the Bcl-2/ Bax family have been identified in plants, ${ }^{92}$ and the potential role of the mitochondria in plant programmed cell death is not known. Therefore, the nature of the effectors involved in the execution of programmed cell death in plants, and their potential relationship with those that operate in metazoans remain to be assessed.

In summary, the observation that plant cells share with animal cells the capacity to self-destruct in response to environmental changes and cell signaling has reinforced the idea that programmed cell death may have played an essential role in the development, survival and evolution of most, if not all, multicellular organisms.

\section{A Red Queen hypothesis for the diversification of programmed cell death}

The rapid induction of programmed cell death in response to microbe entry appears to represent a basic protective response against infection, ${ }^{34}$ that is evolutionarily conserved in plants, insects and mammals. In plants, as mentioned above, the 'hypersensitivity response'103 provides a paradigm for this ancestral defense mechanism. In insects, the requirements of two viral genes encoding caspase inhibitors, P35 and IAP, for efficient infection and propagation of baculoviruses ${ }^{115}$ provides the complementary paradigm that a capacity to repress early induction of programmed death in the infected cell may be a prerequisite for the survival of most, if not all, intracellular parasites. Several infectious pathogens that colonize mammalian hosts have evolved various mechanisms that result in similar repression of programmed death in the cells required for the pathogen replication or persistence, as well as additional mechanisms that conversely induce programmed death in immune effector cells that may target the infected cell for destruction. ${ }^{32-34,40,42,43,116,117}$ Pathogen-mediated induction of immune effector programmed cell death may not only favor immune evasion, ${ }^{39,40}$ but might also allow, through receptormediated ingestion of apoptotic cells by the infected cells, metabolic changes enhancing pathogen replication in its host cells. ${ }^{118}$ Finally, the nature of the programmed cell death phenotype (apoptotic or non-apoptotic) induced by both the infectious pathogen and the host immune system may influence the regulation and effectiveness of the immune response to the pathogen. ${ }^{56,57}$ Because parasite (and host) mediated regulation of programmed cell death may have been crucial in determining the outcome of most hosts/ parasites interactions, and hence the survival of both host and parasite, it is tempting to speculate that on an evolutionary time scale, these host/parasite conflicts involving the control of death signaling pathways may have been instrumental in shaping the diversification of the molecular machinery of programmed cell death.

The 'Red Queen' metaphor has been proposed as a framework for understanding the selective pressures that may drive genetic and phenotypic diversification during co-evolution of predators and preys. ${ }^{119}$ As Lewis Caroll's Alice has to keep running with the Red Queen just to stay in the same place, hosts and parasites have to keep evolving new weapons, defenses, and countermeasures just to stay in the same place, in other words just to stay alive. ${ }^{119}$ Accordingly, if death signaling pathways have represented important targets of host/ parasite evolutionary arms races, it is possible that host/ parasite co-evolution has represented a major selective pressure for both the conservation and the diversification of the genetic regulation of programmed cell death that has occurred in phylogenic diverging branches during the evolution of multicellular organisms. But, whatever the selective pressures exerted on programmed cell death may have been, when did programmed cell death initially emerge?

The first multicellular animals and plants belonging to the eukaryote terminal crown group are believed to have appeared around 0.7 to more than one billion years ago. ${ }^{120,121}$ Were they the first living beings whose cells were endowed with the capacity to self-destruct? Were effectors of cell suicide already present and operational in the first multicellular animals and plants, or were they 
selected later from other ancestral signaling pathways? When did the capacity to self-destruct initially appear?

\section{On the paradigm of a concomitant emergence of programmed cell death and multicellular organisms}

There have been two main reasons that have led to the proposal that programmed cell death emerged with multicellularity. $., 12,17,33,63,92,102,122$ The first pertains to the very nature of multicellular organisms. Cells from multicellular organisms (in contrast to cells from single-celled organisms) are condemned to live together in a given spatial and temporal framework, the body. A multicellular body will survive only if, and as long as, its several differentiated cell types will cooperate in a way that will allow the integrated body to remain adapted to its environment. With the notable exception of the germ cells, no cell from a multicellular organism can outlive the body, nor survive outside the organism. Therefore, the emergence of a genetic program allowing a social form of regulation of cell survival and cell death, through a process of 'altruistic' cell suicide, has been considered as one of the solutions that evolution has provided to the specific problem of multicellular bodies ${ }^{9,12,17,33.63,102,122}$ and attributed to the selective pressure that applied to the emergence of multicellularity, including a process of kin selection between cells sharing the same genome and condemned to live together. ${ }^{92}$

This idea that programmed cell death emerged at the same time as multicellular organisms has been reinforced by the complementary view that genetic programs allowing regulated cell suicide would have been obligatorily counterselected in single-celled organisms. In contrast to the cells from multicellular organisms, each cell from a single-celled organism can be viewed as a germ cell, namely as an individual that carries an identical theoretical probability to transmit its genome to future generations. Therefore, genetic programs favoring 'selfishness' - rather than programs favoring any form of 'altruism' - have been postulated to be the only ones that could have become selected in such organisms. ${ }^{33,102}$ Natural selection does not act directly on genes, but on the phenotypes they allow the cell that encodes them to achieve. Genetic mutation leads to genetic diversification, and hence to phenotypic diversity. Natural selection sanctioned by death is a process of competition between phenotypes whereby genomes allowing for poorly adapted phenotypes do not get transmitted into the next generation, while genomes that allow fitter phenotypes become selected. Simply put, the phenotype represents either the grave of a given genome or its vehicle into the next generation. ${ }^{123}$ Genetically regulated programmed cell death is a phenotype that is characterized by the rapid disappearance of the cell that is expressing it. In other words, genes that encode effectors of programmed cell death can be viewed as allowing a phenotype that is the grave of the genome that expresses them.

According to this view, any mutant gene that might have emerged randomly and allowed regulated cell suicide, would have rapidly and obligatorily led to the counterselection of the individual cell expressing such a mutant gene..$^{33,102}$ Together, these two mutually reinforcing views led to the initial acceptance of the idea that the evolutionary origin of genetic programs of cell suicide has been concomitant with the evolutionary origin of multicellular organisms.

\section{On fascination for a function: from paradigms to paradoxes}

The identification of a central role for cell death in multicellular organisms, and the discovery of its genetic regulation, resulted in a fascination for its function, underlined by the progressive widespread usage of an anthropomorphic terminology ('programmed cell death', 'cell suicide', 'altruistic cell death' ... ), leading to some extent, as previously mentioned, to think of regulated cell death in a conceptual framework of design, purpose and finality. In other words, regulated cell death became implicitly viewed as if it had specifically emerged when it became required to perform its obvious and important functional role in multicellular organisms. When thinking in evolutionary terms, however, such an approach often raises an important paradox. It implies that a complex set of genes and molecular pathways allowing the induction of cell death 'from within' emerged when, and where, it was required. Similar explanations have been previously proposed for the origin of complex genetic programs allowing the emergence of sophisticated organs, such as the eye. It was argued that an eye could have become selected only when complex enough to perform its function (allowing an organism to see), and that, therefore, genes required to build an eye appeared, and became selected, when and where the complexity of an organism allowed such a function to be exerted. Such views are intuitively appealing, but their appeal is related to the fact that they fail to take into account some of the basic and counterintuitive implications of the process of natural selection. ${ }^{123-125}$ It is now believed that eyes (in fact several forms of different eyes) emerged long after the homeotic genes that are involved in building them, ${ }^{126}$ and that these genes became initially selected because they previously allowed other, simpler, phenotypes to be expressed. Moreover, it is important to consider that even the definition of the function 'seeing' is ambiguous. While 'seeing', in the usual sense of the term is a function restricted to some multicellular animals, that requires the capacity to build two complex organs, an eye and a brain, the basic core of the 'seeing' function - the capacity to gather useful information from light, and to respond to it - is an ancestral function performed by photoreceptors that only require the coupling of light-sensitive pigments to signaling pathways, and that is shared by multicellular animals, multicellular plants and several single-celled organisms. But there is more to the difficulty of attempting to assess the evolutionary emergence of what we call a 'function' than such a very long process of 'descent with modifications'. There are some instances in which there is a complete dissociation between the functional advantage that given genes and mechanisms can provide an organism, and the initial reason for which these genes and mechanisms initially emerged and became selected. One of the most spectacular examples of such a dissociation concerns the origin of the genes and molecular mechanisms 
that allow the vertebrate adaptive immune system to perform one of its essential functions, the discrimination between 'self' and 'non-self'. Briefly, the adaptive immune system, that is shared by mammals, birds and jawed-fishes, performs this function by using a huge number (several millions in mammals) of different antigen receptors that are randomly expressed by lymphocytes through a process of somatic $\mathrm{V}(\mathrm{D}) \mathrm{J}$ recombination of a small number of germline genes, and that are subsequently selected through an iterative process of interaction of each lymphocyte with the 'self', whose outcome is coupled to the induction or repression of programmed cell death. ${ }^{28,127}$ Two of the genes whose products allow this somatic $\mathrm{V}(\mathrm{D}) \mathrm{J}$ recombination process are rag1 and rag2 (recombination-activating genes). The expression of rag1 and rag2 is essential for the survival of both the adaptive immune system and its host: human newborns with rag loss of function have no lymphocytes and are condemned to die of infections in the absence of bone marrow graft therapy.

What is the evolutionary origin of these rag genes that allow our immune system to protect us against most of the infectious pathogens? The answer to this question, that was provided four years ago ${ }^{128}$ had never been postulated, and appeared counter-intuitive and paradoxical. Rag1 and rag2 are genes that seem to have initially belonged to an infectious pathogen, a transposon, and were involved in the 'selfish' propagation of this genetic parasite in its hosts. ${ }^{128}$ Around four hundred million years ago, this transposon probably infected the germline of one or several common ancestors of the present day jawed vertebrates, ${ }^{129}$ and in some of the progeny of this ancestor, rag1 and rag2 progressively become involved in the genetic recombination processes that gave rise to the adaptive immune system. Thus, the initial reason for the presence of the genes allowing the emergence of a sophisticated organ whose obvious present day 'function' is to protect us against infectious pathogens, is a retrospectively welcome failure of one of our ancestors to protect itself against an infectious pathogen. In other words, to the question of the origin of the genes that allow the function 'defense against infections', the paradoxical and counter-intuitive answer seems to be: an infection. Therefore, if one wishes to understand the reason for the presence of a complex and somehow counter-intuitive feature of our cells and body, it is often more appropriate to address the question of its possible origin - how and when it may have emerged, and initially become selected - rather than the question of its function the nature of the role it obviously appears to play in our body at the present time. Accordingly, if one believes that programmed cell death is an ubiquitous, highly conserved, and essential feature of most, or all, multicellular organisms, the question of the evolutionary origin of programmed cell death may benefit from being asked in the following way: when and how were genes first selected, that allowed the regulation of programmed cell death? In other words, was there a period 'before' programmed cell death, in which cells died only 'from without', as a result of chance and environmental destruction, and a period 'after' programmed cell death, in which regulated self-destruction, the capacity to trigger premature death 'from within', became one of the intrinsic properties of the cells? Did this frontier arise after the initial three billion years of evolution of single-celled organisms, at the time at which the first multicellular organisms emerged, or did this frontier arise in the kingdom of the single-celled organism, prior to the emergence of multicellular organisms? There are at least two possible ways to address this question. The first - if one believes that the phenotype of programmed cell death would have been counterselected in single-celled organisms ${ }^{33,102}$ - is to consider that the ancestors of the present day executioners were initially ensuring alternate functions (other than self-destruction) in the cell that expressed them. ${ }^{92}$ The second is that gene products allowing the execution of the cell (and gene products allowing the regulated prevention of these executioners) were already present and operational in at least some unicellular organisms. There were at least three theoretical reasons that could allow speculation that a form of programmed cell death may have emerged in singlecelled organisms. ${ }^{130-132}$ Briefly, the first one relates to the fact that single-celled organisms form colonies. It is the survival of the colony, rather than the survival of each of its members, that ensures the perennity of the single-celled organism. Therefore, one may envision that the colony, as a whole, may benefit in some circumstances from the selfdismissal of part of its cells. When thinking in the context of colonies, one can ask the question of the selection of the programmed cell death phenotype from the point of view of the cell that will survive, rather than from the point of view of the cell that will die. In such a context, the question paradoxically becomes whether the lack of a molecular machinery allowing programmed cell death may result in the counterselection of the colony. The second reason relates to the central role that has been attributed to programmed cell death in multicellular organisms, namely the stringent control of cell differentiation, the matching of cell numbers to their environment, and the defense against genetic damage and infections, leading to the elimination of abnormal and infected cells. Cell differentiation, regulation of cell numbers and defense against infection, are not exclusive features of multicellular organisms, but also occur in single-celled organisms (see below) and may, therefore, be optimized by a form of programmed cell death at the level of singlecelled colonies. Finally, a third theoretical reason did not pertain to the potential role of programmed cell death in single-celled organisms, but to the potential nature of the death program and its effector machinery. Briefly, it was based upon the idea that there may not be such thing as a 'bona fide' death program, that is both necessary and sufficient to induce self-destruction, and whose sole possible role is to execute cell death. ${ }^{130-132}$ I will come back later to this last reason.

\section{A paradigm shift: programmed cell death and apoptosis in single-celled organisms \\ Programmed cell death in four diverging phylogenic branches of single-celled eukaryotes}

Various forms of regulated programmed cell death have now been described in nine species of unicellular eukaryotes, 
belonging to four different branches whose phylogenic divergence is believed to range from around two to one billion years ago. These include the kinetoplastid parasites Trypanosoma cruzi, ${ }^{130,133}$ Trypanosoma brucei rhodesiense, ${ }^{134}$ Trypanosoma brucei brucei, ${ }^{135}$ Leishmania amazonensis, ${ }^{136}$ Leishmania donovani, ${ }^{137,138}$ and Leishmania major, ${ }^{139}$ that are believed to be amongst the earliest diverging eukaryotes; the free living slime mold Dictyostelium discoideum, ${ }^{140}$ whose phylogenic divergence is considered of more recent origin, and which represents a particular case of a single-celled eukaryote that can, in certain circumstances, transiently form a multicellular aggregated body and is therefore considered as one of the evolutionary attempts of single-celled organisms at multicellularity; ${ }^{141}$ the free living ciliate Tetrahymena thermophila, ${ }^{142}$ and the dinoflagellate Peridinium gatunense. ${ }^{143}$ Finally, while an 'apoptosis-like' death phenotype can be experimentally induced in yeast, ${ }^{144}$ it is still debated whether yeast can undergo programmed cell death during its normal life cycle. ${ }^{144-146}$

The cell death phenotype of the kinetoplastid, slime mold, ciliate and dinoflagellate share several features with apoptosis, including DNA fragmentation in all, except Dictyostelium discoideum. In these unicellular organisms, as in cells from multicellular organisms, programmed cell death is regulated by extracellular signals. For example, in the kinetoplastid Trypanosoma cruzi and in the ciliate Tetrahymena thermophila, cell survival has been reported to depend on signals provided by other cells from the colony, that are required to repress the induction of a 'default' pathway of programmed cell death. ${ }^{130,142}$ Thus, as in cells from multicellular animals, a form of social control of cell survival and cell death appears to operate at the level of these single-celled eukaryotes. When Trypanosoma cruzi enters the stressful environment that will allow its propagation into another host, programmed cell death becomes an obligate 'default' outcome of a failure of the cycling epimastigote stage of the parasite to differentiate into the G0/G1 trypomastigote stage, the form that migrates between the two infected hosts (the insects and the vertebrates, including humans) and is adapted for survival in each host. ${ }^{130}$ Thus, the regulation of programmed cell death in this single celled eukaryote allows a stringent coupling of appropriate cell differentiation with cell survival. In the three kinetoplastid parasites, Trypanosoma cruzi, Trypanosoma brucei, and Leishmania amazonensis, that cause severe diseases in humans, ${ }^{147}$ programmed cell death is also regulated by signals from their multicellular hosts, such as temperature, and lectins, as well as by components of the host immune system, such as complement and cytokines. ${ }^{130,134,136}$

When the slime mold Dictyostelium discoideum is in appropriate environmental conditions, rich in nutrients, it grows as a colony of cycling single cells. Adverse environmental conditions, such as starving, induce intercellular signaling involving cyclic AMP pathways and leading to cell migration and aggregation, and to the concomitant induction of programmed death in part of the cells ${ }^{140}$ and of differentiation into spores in the other cells. This leads to the development of a multicellular body made of a stalk of dead cells ${ }^{148}$ that support the long-lived, metabolically quiescent spores that will give rise to a new colony of cycling single cells once the environment becomes appropriate. ${ }^{141}$

Finally, programmed cell death seems to play a role in the life cycle of the dinoflagellate Peridinium gatunense, representing an alternate 'default' pathway to the differentiation into cysts that occurs following the seasonal bloom of this species in the spring. ${ }^{143}$

\section{The implications}

The identification of a regulated cell death program inducing an apoptotic phenotype in nine different single-celled eukaryote organisms that belong to four diverging branches of the eukaryote phylogenic tree provides a paradigm for a widespread role for programmed cell death in the control of cell survival, and raises the question of the origin and nature of the genes that may be involved in the execution and regulation of such a process. ${ }^{131,132}$ Evolutionary advantages conferred by such program of self-destruction could include the constant selection for the survival of the fittest cell in the single-celled eukaryote colony, optimal adaptation of the cell numbers to the environment, and tight regulation of cell cycle and cell differentiation in response to environmental changes. In such a context, it is important to realize that the frontiers between multicellular organisms and single-celled organisms may not be as stringent as usually believed. Indeed, the slime mold Dictyostelium discoideum can build multicellular bodies, and the kinetoplastid parasites have evolved a lifestyle that requires their permanent cohabitation with multicellular animal bodies. Thus, the emergence of what we call multicellularity may have only represented an extreme and irreversible manifestation of an ancestral feature on which single-celled eukaryotes have realized countless variations: the social control of cell fates through intercellular signaling at the level of a colony. Particular usage of programmed cell death may involve intercellular interactions even more closely related to multicellularity. For example, in the kinetoplastid parasites, programmed cell death may play an important role in the regulation of the complex interactions between unicellular and multicellular organisms that allow the establishment and persistence of stable host/parasite interactions, and the 'apoptosis-like' phenotype of the parasite death process may reduce the onset of inflammation and favor parasite evasion from the host immune system. ${ }^{132}$ In the slime mold, programmed cell death may be crucial for the development of a transient multicellular aggregated body that favors the survival of at least part (the spores) of the colony.

Interestingly, the finding that a cell suicide program is operational in several unicellular eukaryote lineages explored to date support the seemingly paradoxical view that genetic mutations that would allow cells to escape environmental regulation of their suicide machinery may have become counterselected at the level of the colonies of these single-celled eukaryotes.

\section{On paradigms, 'anomalies' and 'retrorecognition'}

It may be interesting to reflect, for a moment, on how influential a paradigm (such as that of the obligate emergence of programmed cell death in multicellular organisms) can be in 
preventing interpretation of already existing, and sometimes quite ancient, experimental results. Indeed, there have been several experimental findings, some reported more than forty years ago, that could have been interpreted as suggestions that programmed cell death may be operational in singlecelled organisms. ${ }^{141,148-152}$ I believe that the reason why these results were not considered in terms of programmed cell death was not related to a lack of the technical expertise allowing this question to be addressed, but to the weight of the existing conceptual framework that linked the origin and role of programmed cell death to the advent of multicellular organisms. 'Anomalies' in science have been defined as experimental observations that do not fit existing paradigms, and may therefore lead to a change in paradigms that renders the new observation no longer an anomaly. ${ }^{153}$ It has been argued, however, that anomalies can often remain unrecognized for long periods of time. ${ }^{154}$ 'Retrorecognition' has been defined as the phenomenon by which anomalies are recognized only after they have been given an explanation in a new conceptual framework. ${ }^{154}$

There are at least two examples of 'retrorecognition' phenomena that may be relevant to the question of programmed cell death in single-celled organisms.

The first concerns developmental programs that lead to the concomitant formation of dead cells and spores, in the context of transient multicellular aggregated bodies. Such developmental programs have been described several decades ago, not only in single-celled eukaryotes, such as the slime mold Dictyostelium discoideum, ${ }^{141,148}$ but also in prokaryotes, such as Streptomyces ${ }^{149,151}$ and Myxobacteria whose multicellular 'fruiting' bodies can adopt various and striking shapes, including that of a 'tree', in which the 'trunk' and 'branches' are made of dead cells, and the 'leaves' or 'flowers' of long-lived spores. ${ }^{141,150,152}$ In other prokaryotes, such as Bacillus subtilis, developmental programs leading to the concomitant formation of dead cells and spores have also been known to occur, although in the absence of 'fruiting' bodies. All these programs are triggered by changes in environmental conditions, involve intercellular signaling, and are considered as an integral part of the organism life cycle. ${ }^{141,155}$ Although the question of the apoptotic phenotype (and in particular its nuclear features) of such regulated cell death programs could have been raised only in the eukaryote single-celled organisms, the question of the relationship with programmed cell death could have been raised in both the prokaryote and the eukaryote single-celled organisms. During several decades, however, questions about the mechanism, role and genetic control of developmentally regulated cell death programs have remained solely addressed in multicellular organisms. And even when they recently began to be addressed in the context of single-celled eukaryotes, such as Dictyostelium, these questions of the existence of ancestral forms of 'altruistic' programmed cell death have been related to the capacity of these cells to build multicellular bodies, linking the requirement for regulated cell death to evolutionary attempts towards multicellularity. ${ }^{140}$

The second example of 'retrorecognition', although much more recent, is also of interest. Ten years ago, it was reported that a machinery similar to that inducing the nuclear features of apoptosis in cells from multicellular organisms (the nuclear chromatin condensation and the DNA fragmentation into multiples of oligonucleosome length fragments) was present and operational in the unicellular ciliated eukaryote Tetrahymena. ${ }^{156}$ This nuclear execution machinery and program was reported, however, not to be involved in the induction of cell death, but in the elimination of supernumerary old macronuclei during Tetrahymena conjugation, a situation in which these supernumerary nuclei are destroyed, but the cell survives. This finding led to the proposal that programmed cell death, in multicellular organisms evolved from genetic programs that were originally involved, in single-celled eukaryote organisms, in the elimination of supernumerary macronuclei. In other words, the identification in a single-celled organism of part of the machinery allowing self-destruction did not provide a rationale for the investigation of self-destruction in such organisms, but reinforced the paradigm that self-destruction emerged with multicellularity. In cells from multicellular organisms, restricted usage of the apoptotic self-destruction machinery can also achieve means other than cell death and allow particular forms of cell differentiation: in mammals for example, a process of selective induction of apoptotic chromatin and DNA fragmentation, that eliminates the nucleus while allowing the cell to survive is involved in the differentiation of the lens cell in the eye. ${ }^{157} \mathrm{~A}$ similar restricted use of the apoptotic effector machinery appears to have evolved in a single-celled eukaryote, the ciliate Tetrahymena, in addition to its involvement in programmed cell death.

In a more general way, I believe that 'retrorecognition' phenomena may have occurred at several time points in the history of programmed cell death research, and it is possible that this may be related to the counterintuitive nature of the concept of self-destruction. If one attempts to briefly recapitulate the history of the successive views of programmed cell death during the last hundred and fifty years, self-destruction was first considered as an unlikely process; this view was progressively replaced by the idea that programmed cell death may play an essential role in embryonic development, but only in given cell populations, at given time points and at given locations. In other words, programmed cell death became considered, during a very long period, as a price to pay for the complexity of the problems that have to be resolved during embryonic development. More recently, it was proposed that programmed cell death may also be operational, and play an essential role, in adult cells; that dysregulation of physiological cell death programs may play a central role in the pathogenesis of several diseases; and finally that most, if not all, cells from the bodies of multicellular animals are constantly programmed to self-destruct unless signaled by other cells to repress induction of self-destruction. Such a regulation of cell survival was, however, once again considered as an exceptional price to pay for complexity; complexity being in this case the complexity of the multicellular organisms. If one has to consider programmed cell death as a price to pay for the emergence of complexity during evolution, the ultimate, and simplest, 
level of complexity that we are now addressing is that of single-celled organisms. ${ }^{131}$

\section{On the effectors of programmed death in single-celled eukaryotes}

What are the effector pathways involved in the execution of programmed cell death in single-celled eukaryotes? How many different molecular pathways may induce programmed cell death with a phenotype resembling apoptosis? Do unicellular eukaryotes share effectors and regulators of selfdestruction with multicellular animals? Oligonucleosomal-like DNA degradation, an apoptotic feature that depends in mammalian cells on caspase-mediated activation of the CAD endonuclease, ${ }^{86}$ and maybe also on mitochondrial release of endonuclease $\mathrm{G},{ }^{85}$ has been reported as a feature of programmed death in all single-celled eukaryotes mentioned above, ${ }^{130,133,134,136-139,142,143}$ except Dictyostelium discoideum. Caspase inhibitors have been reported to interfere with the development of a multicellular Dictyostelium body, but do not inhibit the developmentally-regulated induction of programmed cell death, ${ }^{158}$ consistent with the lack of chromatin and DNA fragmentation during programmed cell death of this organism. In the dinoflagellate Peridinium gatunense, however, an inhibitor of mammalian cystein proteinases was reported to prevent cell death, and to favor the alternative differentiation into cyst, ${ }^{143}$ but the nature of the protease involved was not identified. In the kinetoplastids, inhibitors of cystein proteinases have been reported to prevent cell death (in Trypanosoma cruzi and in Leishmania donovani), ${ }^{133,137}$ or to prevent the nuclear features of apoptosis when failing to inhibit cell death induction (in Leishmania major). ${ }^{139}$ In the kinetoplastid Trypanosoma cruzi, programmed cell death is also prevented by L-arginine, through a mechanism involving Nitric Oxide (NO) synthasedependent generation of NO. ${ }^{133}$ Mitochondria permeabilization and $\Delta \Psi \mathrm{m}$ disruption have been shown to occur during cell death in both the kinetoplastid Leishmania ${ }^{138,139}$ and the slime mold Dictyostelium discoideum, ${ }^{159,160}$ leading to mitochondrial release of cystein proteinases ${ }^{138}$ and of an AIF homologue, ${ }^{160}$ respectively. While these yet unidentified cystein proteinases and this AIF homologue participate in the respective nuclear modifications and DNA degradation associated with cell death in these two organisms, their potential role in the induction or execution of cell death remains to be assessed. Finally, reactive oxygen species (ROS) induce cell death in the kinetoplastid Trypanosoma brucei brucei, ${ }^{135}$ the yeast Saccharomyces cerevisiae ${ }^{144}$ and the dinoflagellate Peridinium gatunense, ${ }^{143}$ but only in the latter has death been reported to be prevented by an inhibitor of ROS, catalase. ${ }^{143}$ While the genes that allow the execution and regulation of programmed cell death in single-celled eukaryotes remain to be identified, it has been shown that the expression in yeast of the mammalian Bax gene, that induces mitochondrial outermembrane permeabilization and programmed death in mammalian cells, also induces mitochondrial dysregulation and cell death in the yeast; and that the coexpression of the mammalian bcl-2 gene, that counteracts the effect of the bax gene product in mammalian cells, also counteracts Bax-induced death in yeast. ${ }^{161-164}$ It was also reported that the expression in yeast of the Caenorhabditis elegans ced-4 gene (that encodes the adaptor protein that activates the Ced-3 caspase) also induces yeast cell death, and that coexpression of the Caenorhabditis elegans ced- 9 gene (encoding the repressor that inactivates Ced- 4 by binding to it) prevents Ced-4-induced yeast cell death. ${ }^{165}$ This suggests the possibility that at least some of the downstream regulators and/or effectors of self-destruction are shared by single-celled and multicellular organisms. ${ }^{145,146}$

The sequencing of the whole yeast genome, however, has provided a surprising result: no gene encoding a protease with a caspase-related catalytic cleavage site has been identified. ${ }^{92}$ Thus, Ced-4, whose sole known function in Caenorhabditis elegans programmed death is to activate a caspase (Ced-3), is able to cause death in yeast through a process that does not seem to require the presence of a caspase. A possible implication is that Ced-4 has more ways to induce self-destruction than we yet know, for example by forming aggregates or by sequestering ATP. Experiments involving cell death induction by heterologous gene over-expression need, however, to be interpreted with caution. Therefore, it is possible that over-expression of nematode or mammalian pro-apoptotic genes in yeast induces death in ways entirely unrelated, and irrelevant, to their physiological effect in their original species. Yet, provided that this is not the case, another possibility is that recently identified ancestral members of the metacaspase/ paracaspase/caspase superfamily, such as metacaspases, may substitute for caspases in yeast and behave as targets of Ced-4 activation. Interestingly, while genes encoding caspase sequences have only been identified in multicellular animals, genes encoding metacaspases are present in plants, fungi, and several single-celled eukaryotes, including the kinetoplastid parasites, and genes encoding paracaspases, the other members of the caspase/paracaspase/metacaspase superfamily, are present in multicellular animals and plants, and in the slime mold Dictyostelium discoideum. ${ }^{92,111}$ As previously mentioned, however, nothing is yet known about the potential capacity of the paracaspases and metacaspases to participate in cell death induction. Genetic screening has not revealed to date the presence of genes encoding homologues of the Bcl-2/Bax family in any single-celled organism. It should be noted, however, that a protein with Bcl-2-like anti-apoptotic properties, that prevents human cell programmed death by controlling mitochondria permeabilization, but has no sequence homology with any known member of the Bcl-2 family, nor any other known programmed cell death repressor, has been recently identified in a human virus, cytomegalovirus, ${ }^{166}$ suggesting that there may exist other protein families with Bcl-2-like functional activities that remain to be identified.

Also, the mitochondrial flavoprotein AIF, that has caspase-independent pro-apoptotic activity in mammalian cells, is broadly conserved in single-celled eukaryotes. ${ }^{167}$ Provided that ontogeny may, to some extent, recapitulate phylogeny, the recent finding that AIF participates in the earliest induction of programmed cell death occurring during mammalian development (the epiblast cell death leading to cavitation in the blastocyte $)^{90}$ suggests that AIF 
homologues may represent ancestral effectors of programmed cell death. Their potential role in single-celled eukaryote death, however, has not yet been assessed, and mitochondrial executioners other than AIF may exist. Indeed, while a homologue of AIF is present in Saccharomyces pombe, but lacking in Saccharomyces cerevisiae, ${ }^{167}$ Bax has been reported to induce death in both the Saccharomyces cerevisiae and Saccharomyces pombe yeast species. ${ }^{146}$ Finally, the mitochondrial endonuclease $G$, that seems to induce caspase-independent internucleosomal cleavage of genomic DNA in both mammalian ${ }^{85}$ and C. elegans cells, ${ }^{101}$ and the mitochondrial serine protease Omi/HtrA2, that may induce both caspase-dependent and caspase-independent cell death ${ }^{83}$ seem evolutionarily conserved in single-celled eukaryotes ${ }^{83,168}$ and might therefore also represent candidate ancestral effectors involved in caspase-independent cell death. In summary, we still do not know the molecular nature of the effectors of self-destruction that operate in single-celled eukaryotes. And we do not know whether similar or different effectors operate in divergent branches of these organisms.

\section{On limits in evolutionary time travelling: all presumed ancestors are contemporaries}

When did the capacity to self-destruct emerge in single-celled eukaryotes?

Any attempt to travel into the past raises intrinsic problems and limitations, due to the fact that all the single-celled organisms that surround us, however ancient their phylogenic divergence may be, are not ancestors but contemporaries that have been subjected to numerous and lengthy evolutionary pressures. Another problem is that the branching pattern of the eukaryote phylogenic tree, initially based on small subunit ribosomal RNA gene sequences ${ }^{120}$ and considered robust, has recently been questioned, ${ }^{169}$ raising doubts about previous estimates of divergence timepoints, and hence about classifications into 'early' and 'recently' diverging single-celled eukaryotes. ${ }^{169}$

Currently, there are several possible explanations for the existence of programmed cell death in at least nine single-celled eukaryote organisms belonging to four different lineages that diverged during a still elusive timeframe ranging between two and one billion years ago. The first possible explanation is that programmed cell death is an ancient and conserved feature in most, if not all, singlecelled eukaryote organisms, and that programmed cell death emerged at the time - or prior to the time - of the emergence of the first eukaryotes. If this were true, programmed cell death should be found to be present and operational in most, if not all, the branches of the eukaryote phylogenic tree. Accordingly, one way to attempt exploring such possibility is to investigate how many single-celled eukaryotes are endowed with the capacity to self-destruct. But the interpretation of such findings may still remain elusive. If some single-celled eukaryote organisms are found to be devoid of the capacity to self-destruct, this will not allow excluding the possibility of a form of reductive evolution, namely a secondary loss of an ancient evolutionary shared feature.
Conversely, if all single-celled eukaryote organisms are found to have operational physiological self-destruction programs, this will not exclude the possibility of strong selective pressures leading to recent parallel acquisitions of programmed cell death.

In this context, the kinetoplastid parasites provide an interesting example. Kinetoplastids emerged before the first multicellular animals, but the ancestors of present day trypanosomes and leishmania have subsequently evolved into obligate parasites of both invertebrate and vertebrate hosts. Therefore, it is possible that the origin of programmed cell death and of its apoptotic phenotype in these kinetoplastid parasites does not predate the origin of programmed cell death and apoptosis in their invertebrate and vertebrate hosts, but has resulted from selective pressures involved in the establishment of the complex interactions between unicellular and multicellular organisms that allowed the emergence of parasitism, and/or from the horizontal transfer of host genes. This important question as to whether the emergence of an apoptotic death program in a kinetoplastid may be related to its obligate parasite nature may be addressed by investigating the closely related kinetoplastid Bodonids that include both parasites and free-living non-parasite single-celled organisms. ${ }^{147}$ But whether the non-parasite Bodonids directly derive from the early non-parasite kinetoplastids, or from more recent parasite ancestors that subsequently became free living, still remains a matter of speculation. In summary, it is possible that the ancestors of the nine present day single-celled eukaryotes that are endowed with the capacity to undergo programmed cell death were initially devoid of the ability to self-destruct, and that programmed cell death became selected in different branches of the phylogenic tree in response to selective pressures that may have involved competition, interaction and cooperation with more recently diverging eukaryotes. Such a process of parallel evolution leading to a somehow recent acquisition of programmed cell death may have happened either through horizontal gene transfer, through the building of similar cell death machinery by using a common molecular framework of conserved proteins of shared ancestry, or through the building of different cell death machinery by using diverse proteins through a process of convergent evolution. But, whatever the molecular nature of such effectors may be, how did unicellular organisms select for the complex genetic programs allowing self-destruction, as well as for the coupling of cell survival to the repression of self-destruction? This is the question that I will now try to address.

\section{From the question 'when' to the question 'how'}

I will now argue that there are ways to look at the nature and role of programmed cell death that are very different from those we have been accustomed to by thinking in the context of multicellular organisms.

The first example that I will discuss concerns various forms of regulated cell death that have been described in various bacterial species for several decades, but that were not considered, until recently, ${ }^{130,170-173}$ as potential 
examples of programmed cell death. Such primitive forms of programmed cell death had been described not only, as mentioned above, in circumstances that include the terminal differentiation of Myxobacteria, Streptomyces and Bacillus subtilis, but also, in several circumstances that involve competitions between bacterial colonies from different species, as well as competitions between plasmids or viruses and bacteria within a given bacterial colony.

\section{Two hypotheses for the evolutionary origin of programmed cell death: the 'addiction' hypothesis and the 'original sin' hypothesis}

\section{From 'murder' to 'self-destruction': the 'addiction' hypothesis}

On toxins, antidotes and interspecies bacterial killing When competing for the control of environmental resources, several bacterial species use strategies based on the killing of other bacterial species. They do this by secreting toxins (antibiotics) that induce the death of other bacteria. Such toxins include colicin E1, colicin E7, microcin (Mcc) B17, and streptomycin, and act either by inserting pores in the bacterial membrane, or by damaging bacterial DNA through direct or indirect mechanisms, involving the modulation of the activity of enzymes that participate in the modification of DNA topology, such as DNA gyrases. ${ }^{171,174}$ The reason why bacteria can release a toxin that kill other bacteria without getting killed themselves is that they synthesize an antidote that is not secreted and protects them against the lethal effect of the toxin. ${ }^{171,174}$ The selection for killer genes encoding toxins used in offensive evolutionary arms race against other bacterial species, and the concomitant selection for genes encoding antidotes allowing self-protection is a process that provides the bacteria with both executioners and repressors that can prevent the effect of these executioners. These genetic modules bear surprising resemblance to the basic core of the genetic modules that allow, in cells from multicellular organisms, the regulation of programmed cell death. In other words, the ability to self-destruct may have simply evolved as a consequence of a capacity to kill others. But there are other important aspects of an evolutionary arms race in bacteria that also pertain to the potential evolutionary origin of programmed cell death.

On toxins, antidotes, and plasmid propagation In the prokaryote world, competition for environmental resources is not restricted to competition between different bacterial species. Infectious agents, such as plasmids and bacteriophage viruses, also compete with bacteria: in this case, it is the bacteria itself that is the resource, and the evolutionary arms race involves the spreading of the heterogeneous mobile genetic elements in the bacterial colony. Strategies allowing plasmids and bacteriophages to propagate in the bacterial colony involves various mechanisms that allow spreading from one bacteria to another. ${ }^{175}$ One of these strategies depends on the presence, in the infectious agents of genetic modules encoding a toxin and an antidote. In fact, most toxin/antidote modules that allow bacteria from a given species to kill other bacterial species are not encoded by the bacterial chromosome, but by plasmids that infect the bacteria. ${ }^{170,171,174}$ As previously mentioned, the toxin is released by the infected bacteria while the antidote is retained in the cell. Thus, the first targets of the toxins are the uninfected neighboring bacteria from the colony. This strategy allows a dramatic propagation of the plasmid in the colony, since it couples infection with survival, and induces the elimination of all uninfected bacteria. Such strategy not only enforces efficient propagation, it also induces some level of irreversibility. Indeed, if the plasmid becomes disabled or destroyed by one of the infected bacteria, or if some daughter cell escapes receiving the plasmid from her mother cell, these 'cured' bacteria, that cannot anymore synthesize the antidote, will be killed by the neighboring infected bacteria that still release the toxin. Thus, whatever subsequent advantage the plasmid encoded toxin/antidote module may confer to the colony, such as an edge in interbacterial species competition, the first reason for their persistence is that the colony, as a whole, has become 'addicted' to their expression.

But there are still more extreme forms of plasmidmediated addiction strategies. They do not function in a paracrine manner, at the level of the colony, by setting a process of death 'from without'; rather, they function in an autocrine manner, at the level of each bacterium, by setting a process of death 'from within' that shares striking similarities with programmed cell death.

On 'addiction modules' as genetic programs controlling death 'from within' An extreme plasmid or virus strategy relies on mechanisms enforcing the bacterial retention of the infectious agent by setting up the obligate death 'from within' of any bacteria that will inactivate or reject it. Several plasmids achieve this by encoding both a toxin and an antidote. There are various forms of toxins and antidotes involved, but they all share two similar features: firstly, neither the toxin nor the antidote are secreted by the infected cell; secondly, the toxins are stable and long-lived, the antidotes are unstable and short-lived. ${ }^{170,171,176}$ Following infection, the bacteria continuously expresses the plasmid gene that encodes the toxin and the plasmid gene that encodes the antidote. If the plasmid becomes disabled or rejected, or if some of the daughter cells of the infected bacteria escape receiving the plasmid from their mother cell, both the toxin and the antidote stop being synthesized in the 'cured' cell. Since the half life of the toxin exceeds that of the antidote, this will lead to the obligate and programmed death of the 'cured' cell.

The exogenous genetic modules that encode this family of toxins and antidotes have been called 'addiction modules', because each bacteria, once infected, becomes individually addicted to the continuous presence and expression of the infectious genetic elements. The death process that is triggered by the inactivation or loss of these addiction modules has been called 'post-segregational killing', because all plasmid-free bacterial segregants are condemned to die. Although the addiction modules are of foreign origin and are not encoded by the bacterial chromosomes, they endow the infected bacteria cell with 
a genetic program allowing the induction of a process of death 'from within', that may be considered as a regulated form of self-destruction.

'Self', in this case, however, refers to a symbiont, a chimera, a new community made up by the bacteria and the plasmid. The usual view of symbiosis is that of a cooperation process, whereby the merging provides mutual benefits to the partners. Here we see that a symbiosis can be achieved in a different and more radical way, by coupling separation with obligate death. And it is possible to see some similarities between this 'addictive' symbiotic process and the process we call 'programmed cell death'. Indeed, this addiction-regulated death process is a 'default' pathway involved in a form of 'social' control of survival and death, that does not operate between different cells at the level of a colony, but more simply between a cell and an infectious agent, at the level of a given infected cell.

What is the nature of the toxins and antidotes encoded by the addiction modules, and how is their respective halflife determined? All toxins are long-lived proteins; antidotes come in two kinds. The first kind of antidotes are labile antisense RNA of short half-life, that block the translation of the toxin encoding RNA, as exemplified by the Hok/Sok module, in which the Hok toxin protein induces lethal membrane depolarization, and the Sok antisense RNA prevents translation of the Hok encoding RNA. ${ }^{172,176}$ Most known antidotes, however, are proteins. Some antidotes are methylases, that protect DNA against direct fragmentation by the type II-restriction enzyme toxins; other antidotes act by protecting DNA against indirect damage induced by the toxin (through the modulation of the activity of enzymes such as DNA gyrases), as exemplified by the $\mathrm{CcdB} / \mathrm{Ccd} A$ addiction modules or by the Kid-PemK/Kis-Pem1 addiction modules. ${ }^{170,171}$ In all these models in which the interaction of the toxins and the antidotes occur at a protein/protein level (including the ParE/ParD and the Doc/Phd addiction modules), the reason why the antidote protein has a shorter half-life than the toxin protein is that the antidote is cleaved by a protease. Surprisingly, in all the known models, the protease is not encoded by the plasmid, but the plasmid addiction module relies on constitutively expressed bacterial chromosomal-encoded proteases, which include the Lon- or the CIpP-ATP-dependent serine proteases. ${ }^{170}$ Thus, the efficiency of the addiction module depends on a form of enforced cooperation, inside a given bacterium, between gene products expressed by the infectious agents and gene products constitutively expressed by the bacterial chromosome.

The reason why these bacterial serine proteases are constitutively expressed in the bacterial targets of the plasmid is that they appear to perform essential roles in bacterial survival, that will lead to the counterselection of protease loss of function mutants that may have otherwise escaped plasmid addiction. In some bacterial species, some of these essential roles performed by the Lon and ClpP proteases have been uncovered. For example, they are required for bacterial cell division to proceed, through the temporally regulated proteolysis of methylases required to duplicate chromosomal DNA; as well as for bacterial cellcycle regulation, through proteolysis of the cell cycle regulator SulA in adverse environmental conditions that lead to DNA damage and/or to the induction of an SOSstress response. ${ }^{177}$

Because it seems obvious, when thinking of programmed cell death in multicellular organisms, to consider self-destruction as an 'altruistic' cell behavior, the question of the nature of the evolutionary constraints that may have led to the selection of the genetic modules allowing programmed cell death has been equated with the question of the nature of the evolutionary constraint that may have favored the selection of 'altruistic' cell behavior.9,17,18,33, 63,102 Through a radical change in perspective, we have now seen that the emergence of programmed cell death can be envisioned as resulting from a selective spreading advantage conferred by genetic modules regulating cell death and survival to the genomes able to express them. In this context, plasmid-encoded toxin/antidote modules can be seen as genetic modules that allow the propagation of the plasmid that encodes them. Such modules may induce death in an autocrine way, as do the 'addiction modules'; or they can induce death in a paracrine way, as do the modules involved in inter-bacteria species killing. In both instances, they enforce the propagation of these genetic modules by inducing the elimination of the bacterial cells that do not express them.

Such toxin/antidote modules, by coupling the survival of the infectious genome to that of the bacterial genome, may have provided several selective advantages to the infected bacterial cell colony: in addition to an edge in interbacterial species competition, as previously mentioned, they may have provided bacteria with defense mechanisms against superinfection by other plasmids or bacteriophages. ${ }^{178}$ It is easy to see how such strategies can be combined in diverse and increasingly complex manners. But overall it is important to realize that whether toxin/antidote modules provide selective advantages to the bacterial cell that expresses them, whether they provide no selective advantage at all, or whether they are detrimental to the cell that carries them, the basic reason for which they propagate is, once again, that they are addictive.

Natural selection can favor the propagation of given genes for the sole reason that they are successful at propagating themselves, while being of no advantage, or sometimes while even being detrimental, to the fitness of the organisms that carry them. Such genes have been called 'selfish genes'. ${ }^{179-}$ 181 It is interesting to think that the genetic modules that are now involved in the regulation of what we call 'altruistic' regulated programmed cell death may have initially emerged and become selected as 'selfish genetic modules', for the sole reason that encoding an executioner and an inhibitor of the executioner just made them good at propagating themselves. ${ }^{182}$ Is there any evidence for such an evolutionary scenario? Is there any indication that such 'selfish' toxin/antidote addiction modules may have subsequently become selected by bacterial cells and recruited into an 'altruistic' form of programmed cell death?

Towards the emergence of programmed cell death: 'self addiction' modules and regulated self-destruction A bacterial chromosome-encoded addiction module has been 
discovered in Escherichia coli. ${ }^{183}$ This genetic module, that is not associated with any other plasmid gene, encodes the long-lived stable toxin MazF, that induces DNA damage, and the short-lived antidote MazE, that counteracts the toxin. The MazE protein antidote is short-lived because it is constantly cleaved by the constitutively expressed bacterial CIpP ATP. dependent serine protease. In appropriate environmental conditions, the MazF toxin, the MazE antidote and the ClpP proteins are constitutively expressed, leading to a constant de novo synthesis of the toxin, and to a constant de novo synthesis and cleavage of the antidote, a dynamic equilibrium that allows bacterial survival. In adverse environmental conditions, such as nutrient shortage, intracellular signaling, in particular an increase in $3^{\prime}, 5^{\prime}$-bispyrophosphate, leads to the inhibition of the MazE/MazF operon: both the MazE and MazF proteins stop being synthesized. The ClpP protease continues to be expressed, the residual MazE antidote continues to be cleaved, and bacterial self-destruction occurs, as a consequence of MazF toxin-mediated irreversible DNA damage. $^{183}$

This finding is consistent with a multistep scenario for the evolutionary emergence of programmed cell death, ${ }^{131}$ in which infectious 'selfish' gene modules encoding a toxin and an antidote become at some time points integrated at the bacterial chromosomal level. Accordingly, the transfer into the bacterial chromosome of the plasmid 'addiction' genetic module encoding the toxin and the antidote may have represented one of the means that allowed bacteria that subsequently rejected the plasmid to become 'cured' while avoiding death. Such cured bacteria were then probably condemned to continuously express the toxin and the antidote, a form of 'program' whose sole function was to enforce the maintenance of these two 'selfish' genes now encoded by the bacterial chromosome. At some subsequent time points, the emergence of a regulation of the expression of these 'selfish genes' in response to extracellular signaling may have allowed their use as inducers of cell death in adverse environmental conditions. Such 'altruistic' regulated use of programmed cell death may have provided selective advantages to the bacterial colony by allowing, in starving conditions, the survival of a part of the cell population at the expense of the rapid dismissal of others. Such a selfdestruction process does not only provide the surviving cells with a greater share in the available external resources, but also with the additional nutrients represented by the dying cells. The 'selfish' addiction module has now become an integrated part of the genome of the bacterial colony and has become involved in a form of 'altruistic' regulation of cell survival and cell death that strongly resembles programmed cell death. ${ }^{183}$

Interestingly, this form of programmed cell death in bacteria shares another feature with programmed death in cells from multicellular organisms: it is a 'default' pathway. Because the bacterial cells constitutively express the executioner protein allowing induction of cell suicide, cell survival constantly depends on the expression of a dominant but short-lived antidote protein that prevents activation of the executioner. This programmed cell death module acts in fact as a 'self-addiction module': once it has begun to be expressed, cells can only survive by continuing expressing it. Accordingly, a surprising view of programmed cell death emerges when one fully realizes that it is not the expression of the programmed cell death module that induces cell suicide, but its repression; self-destruction in Escherichia coli is a phenotype that results from the regulated repression (in response to environmental signals) of a self-addiction genetic module encoding a toxin and an antidote. But the coupling of such a repression of the addiction module to given exogenous signals could have become selected only if it allowed the concomitant survival of at least some members of the colony. In other words, such a program has to be socially regulated at the level of the colony population in order not to lead to the indiscriminate self-destruction of all the bacterial cells in response to adverse environmental conditions. How may such a decision become integrated at the level of the bacterial colony? How may bacteria decide, at a single-cell level, when to die and when to survive?

How to decide when to die: On quorum sensing and cell differentiation in bacterial colonies Although this is often neglected, the ability to differentiate is a feature of most, if not all, single-celled organisms, including prokaryotes. In bacteria, as in single-celled eukaryotes, coordinated changes in gene expression lead to changes in cell cycle regulation, in morphology, and in intercellular signaling. ${ }^{155,184-187}$ Striking aspects of differentiation in bacteria include fruiting body formation in Myxobacteria, light production in luminescent Vibrios, spore formation in Myxobacteria, Streptomyces and Bacilli; and asymmetric cell division in Bacillus subtilis and Caulobacter crescentus. Several other forms of differentiation have been described in bacteria, including the SOS stress and repair response, and the formation of biofilms that constitute complex multicellular communities. ${ }^{188}$ One of the most ubiquitous environmental signals that trigger differentiation in bacteria is nutrient shortage. ${ }^{171,184-186}$ In appropriate environmental conditions, bacteria undergo exponential vegetative growth. Upon nutrient shortage, a developmental program is triggered in most bacteria species, that leads to the concomitant induction of cell differentiation in a part of the population, and of cell death in the rest of the colony. In Myxobacteria, Streptomyces and Bacilli, nutrient shortage induces the terminal differentiation, followed by the death, of a part of the cells from the colony; these terminally differentiated cells helping the other part of the cells from the colony to differentiate into long-lived non-cycling and highly resistant spores. ${ }^{173,184,186}$

Although environmental changes represent the initial and necessary trigger for the complex set of modifications that will lead to this process of alternate and complementary differentiation, the environmental signals by themselves are not sufficient: an additional step of intercellular signaling is required, that will lead to a coordinated set of changes in gene expression. ${ }^{155,186}$ In Myxococcus xanthus, for example, the decision upon nutrient shortage to either continue to grow (at a reduced rate) or to trigger a developmental program that will lead to programmed cell death and sporulation, depends on two limiting factors: the density of cells in the bacterial colony, and the density of individual 
cells, in that colony, that will respond to the environmental change. Individual cells respond to nutrient shortage by expressing genes that allow the synthesis and release of a given 'quorum factor' (a kind of pheromone) that binds quorum sensors (receptors) that are expressed by each bacterial cell of the colony and are sensitive to the concentration of quorum factor present in the environment. Quorum factor binding induces gene expression only when a threshold concentration of quorum factor is reached, that greatly exceeds the quantity of quorum factor that can be synthesized by any given cell. ${ }^{186}$ In other words, differentiation results from a collective decision, that depends on the number and proximity (on the density) of neighbor cells that have taken the individual decision to favor differentiation. Such a process provides an interesting model for understanding how important changes that will affect the future of the whole colony are not taken at the level of any individual cell, but integrated at the level of the colony. As most 'altruistic' kin interactions, this social behavior is confronted with subversion by cheating mutants, as exemplified by the identification of Myxococcus mutants that contribute more spores and less dying cells when mixed with wild colonies. ${ }^{189}$ But besides the problems raised by such a competition, a more basic question is this: how do these collective changes lead to the specification of alternate cell fates that allow restricting terminal differentiation and self-destruction to only a part of the bacterial population? I will now argue that there is a striking example that illustrates how such a complex process can be achieved.

A model for the resolution of the paradox of self-destruction in single-celled organisms: asymmetric cell division in Bacillus subtilis A cell suicide program will become counterselected unless it is regulated in such a way that the sacrifice of some individuals in a unicellular colony will benefit (or at least will not prevent) the survival of other members of the colony. As mentioned above, a coupling of programmed cell death regulation to that of cell differentiation and of intercellular signaling represents one of the essential steps towards such a solution. But how is this solution achieved? Bacillus subtilis provides a spectacular and extreme example of how such a major theoretical problem concerning the evolution of programmed cell death in unicellular organisms can be solved. ${ }^{132,190,191}$

In favorable environmental conditions, Bacillus subtilis undergoes vegetative growth through symmetrical cell division. In adverse environmental conditions, such as nutrient shortage, Bacillus subtilis undergoes a complex developmental program whose initiation depends, as mentioned above, on cell density and on the concentration of released quorum factors. ${ }^{186}$ When initiated, this program begins with a process of asymmetric cell division. The septum cannot anymore be positioned at the middle of the cell (as during vegetative growth) but only closer to one pole of the developing cell. Cell division, however, is not completed: the polar septum separates the cells in two different territories, and the two asymmetric future cells remain attached one to the other. ${ }^{184,192,193}$ The biggest part of the cell, called the mother cell, will become terminally differentiated and will subsequently undergo a form of programmed death, after having helped the smaller part of the cell, called the pre-spore cell to become a non proliferating long-lived spore. In other words, the initiation of a process of asymmetric cell division allows Bacillus subtilis, at the level of each single cell, to undergo a developmental program leading to the emergence of the simplest possible form of a transient multicellular organism, made up of two cells that have respectively differentiated into the equivalent of a somatic cell (the mother cell) and into the equivalent of a germ cell (the spore). Because each single cell in the colony becomes the coupling unit, differentiation will obligatorily lead in the colony to an equal number of self-destructing cells and of surviving cells. An essential aspect in Bacillus subtilis of the genetic regulation of cell differentiation that will lead to the coupling of sporulation and programmed cell death is the complex intercellular regulation of the expression and activation of at least four transcription factors, $\sigma^{\mathrm{E}}$ to $\sigma^{\mathrm{K}} .{ }^{184}$ The initial step of symmetry breaking (asymmetric division) will have the important consequence of leading to a different concentration of proteins in the pre-spore cell and in the mother cell. Briefly, the higher concentration, in the mother cell, of proteins such as the SpollE phosphatase will induce the selective activation of the $\sigma^{\mathrm{F}}$ transcription factor in the prespore cell. ${ }^{194}$ Activated $\sigma^{\mathrm{F}}$ from the pre-spore cell will then lead to the activation of the $\sigma^{\mathrm{E}}$ factor in the mother cell, that will in turn activate the $\sigma^{\mathrm{G}}$ factor in the pre-spore cell; the $\sigma^{\mathrm{G}}$ factor from the pre-spore cell will then activate the $\sigma^{\mathrm{K}}$ in the mother cell; finally, the $\sigma^{\mathrm{K}}$ factor from the mother cell will lead to the final differentiation of the pre-spore cell into a spore cell, and to the expression, in the mother cell, of the cwlc autolysin that will lead to the self-destruction of the mother cell. $^{195}$

Such a sophisticated temporal and spatial regulation of gene expression provides a spectacular example of how the coupling of programmed cell death to intercellular communication can avoid the death of the whole colony in adverse environmental conditions, by ensuring that the sacrifice of one half of the progeny will be coupled to the survival of the other half of the progeny.

Symmetry breaking and the regulation of programmed cell death Sporulation occurs only in some bacterial species, but as previously mentioned, cell differentiation associated with cell death is a usual response of most bacterial species to adverse environmental conditions. The view that I have proposed is that Bacillus subtilis represents an example (rather than an exception) of the intercellular communication that may operate (maybe in a more stochastic manner) in most single-celled organisms, and may allow the breaking of symmetry required for the coupling of programmed cell death to survival at the level of the colony. ${ }^{132,191}$ The polarization of initially stochastic symmetry breaking has been proposed as a crucial process in the emergence of self-organization and complexity. ${ }^{196,197}$ Accordingly, the view presented here implies that it is also one of the crucial mechanisms that has allowed the emergence of an evolutionarily stable form of programmed cell death.

While asymmetric cell division is an important and conserved mechanism involved in cell differentiation in 
bacteria $^{192,194}$ and single-celled eukaryotes, ${ }^{198,199}$ it is not the sole mechanism allowing the breaking of symmetry at the level of a colony. In the single-celled eukaryote Dictyostelium discoideum, for example, independently of the numbers of the cells that have initially aggregated in response to adverse environmental changes and will develop a multicellular body, the respective proportions of cells that will become surviving spores and dying stalk will be conserved. In contrast to Bacillus subtilis, however, the numbers of cells that will survive is not equal to the number of cells that will die, the former representing two-thirds of the cells, and the latter one-third. ${ }^{200}$ And, accordingly, in contrast to Bacillus subtilis, this two-thirds/one-third repartition does not result from the initiation of a process of asymmetric cell division. It seems that each cell of the Dictyostelium colony, at the moment it begins to join the others, has the same initial stochastic probability to become a dying or a surviving cell. During a few hours, intercellular signaling, acting on initially random differentiation choices, seems to achieve a fine tuning of the respective proportion of future spore and stalk cells, through the release of molecules that, upon reaching threshold, influence the differentiation process in neighboring cells. ${ }^{200}$ Thus, Bacillus subtilis and Dictyostelium discoideum suggest that there may be various ways, at the level of a given colony, to achieve the breaking of symmetry along a line that will segregate the living from the dying, and to ensure that the death of a part of the cells will be coupled to the survival of the rest of the colony. Assessing to what extent the mechanisms involved in such a 'social control' of symmetry breaking and programmed cell death in single-celled eukaryotes may be conserved in multicellular organisms is a fascinating question that remains to be investigated.

In summary, the evolutionary scenario that I have outlined above suggests a multi-step process for the emergence of programmed cell death in bacteria. The most commonly accepted proposal for the origin of the eukaryote cell - a symbiosis that arose from the capture of a bacteria by a proto-eukaryote cell ${ }^{201,202}$ or from a fusion between an $\alpha$ proteobacteria and an archaebacteria ${ }^{203}-$ suggests the hypothesis that programmed cell death has undergone a further step of stabilization in the first eukaryote cell, in which an evolutionary arms race between two heterogeneous genomes condemned to live together (the proto-mitochondrial bacteria and the proto-eukaryote cell), led to a resolution of these genomic conflicts and to enforced cooperation through a process of reciprocal addiction. ${ }^{131,132}$

Symbiosis and the evolution of programmed cell death: the eukaryote cell, the nucleus and the mitochondria Most eukaryote cells - from single-celled eukaryote organisms to multicellular animals and plants - harbor at least two genomes: the nuclear genome, that contains most of the cellular genes, and the cytoplasmic organelle genomes, that are small circular DNAs present in the mitochondria (singlecelled plants and multicellular plants contain an additional organelle genome, the plastid chloroplast circular DNA). ${ }^{204,205}$ The size of the mitochondrion genome greatly varies, depending on the organism, from around $16 \mathrm{~Kb}$ in mammalian cells, to around $80 \mathrm{~Kb}$ in the Saccharomyces cerevisiae yeast and to more than $500 \mathrm{~Kb}$ in some multicellular plants. Numbers of mitochondria per cell also greatly vary depending on the organism, ranging from a giant unique mitochondrion kinetoplast in the kinetoplastid protozoan single-celled eukaryotes, such as the trypanosomes, to several hundred mitochondria per cell in several single-celled eukaryotes and in multicellular animals. Mitochondria play an essential role in eukaryote cells from single-celled and multicellular organisms: they perform aerobic metabolism, that allows energy production through ATP synthesis by a respiratory process that involves an electron transport chain and a chemiosmotic process. Loss of mitochondrial function forces cells to rely only on anaerobic metabolism, which may be lethal in most cells from multicellular animals (but mature human erythrocytes, that lack mitochondria, represent an interesting exception) and, probably, from most single-celled eukaryote (but Giardia and Microsporidia, that lack mitochondria, represent interesting exceptions). Each mitochondrion is bound by two highly specialized membranes that create two separate compartments, the internal matrix space and the intermembrane space. Mitochondria (as well as chloroplasts) have several striking features: (i) they are not made de novo by the cell, but always arise by growth and division of preexisting mitochondria; (ii) in organisms endowed with sexual reproduction, such as yeast and multicellular animals, mitochondrial genes show a non-Mendelian (or cytoplasmic) inheritance pattern, with biased uniparental maternal inheritance in multicellular animals; (iii) the mitochondrial DNA organization, as well as the transcription and translation apparatus involved in mitochondrial protein synthesis, are very different from those of the nuclear genes; finally (iv) the mitochondrial genome from most organisms is devoid of introns, the fidelity of mitochondrial DNA replication is lower than that of the nuclear genome, and there are even some differences between the mitochondrial genetic code and the so-called 'universal' genetic code.

All these features strongly suggest that mitochondria are of ancient bacterial origin, and support the hypothesis that mitochondria arose from symbiosis between bacteria able to perform aerobic metabolism and ancestors of eukaryote cells. ${ }^{201-203}$ According to this hypothesis, eukaryote cell ancestors were initially anaerobic single-celled organisms without mitochondria that may, as many present day archaebacteria, have used $\mathrm{H}_{2}$ as their sole source of energy (ATP), and either $\mathrm{CO}_{2}$, methylamine, formic acid or acetate as their sole carbon source. ${ }^{203,206}$ Around two billion years ago, significant amounts of oxygen are believed to have entered the earth's atmosphere, as a consequence of the metabolism of oxygen-producing photosynthetic cyanobacteria. The endosymbiont hypothesis postulates that the anaerobic ancestors of eukaryote cells then acquired mitochondria through the capture of bacteria of $\alpha$-proteobacterial origin that possessed oxidative phosphorylation systems that became subverted by the eukaryote cell for aerobic metabolism. ${ }^{201,202}$ Interesting variations have been recently proposed on this scenario, but they do not change most of the basic implications of the endosymbiont hypothesis. ${ }^{203,206}$ 
On 'addiction' in the eukaryote cell Present day mitochondria and eukaryotic cells are condemned to live together, and this symbiotic equilibrium is usually viewed as a consequence of a mutual cooperation process between the ancestors of the eukaryotic cells and the aerobic bacteria they captured. But an alternate view, that may be more appropriate, is to consider that such enforced cooperation equilibrium rather results from the stabilization of an initial host/pathogen conflict. Indeed, there are still several examples, in various organisms, of intracellular bacteria using eukaryote cells as an appropriate environment for their 'selfish' propagation. This is true of some of the pathogenic bacteria,such as Ricketsia, Listeria and Schigella, that invade mammals and replicate in their cells by subverting host cell signaling processes. ${ }^{207}$ But there are also more complex ways in which bacteria subvert eukaryotic organisms. In several crustaceous species and insect Hymenoptera species, bacteria such as Wolbachia are able to infect oocysts and to persist in these cells without killing them, resulting in a complex host/parasite equilibrium that can lead either to changes in the phenotypic sex of the infected organism, to male sterility, or to a complex process of speciation through the prevention of mating between organisms which are infected by different bacterial strains. ${ }^{208,209}$ Striking and complex interactions with bacteria can also occur in single-celled eukaryote organisms. First, the amoebae palomyxa palustris, one of the rare single-celled eukaryotes that lack mitochondria, is a symbiont that contains aerobic bacteria in its cytoplasm; and it is these bacteria that perform the respiratory activity required for the aerobic metabolism of the amoebae. ${ }^{204}$ Second, a bacterial infection of laboratory cultures of amoebae has been reported to lead to the emergence of an endosymbiotic association, in which several thousands of bacteria reproduce in the cytoplasm of each amoebae cell: the amoebae have become dependent on the existence of the bacteria in their cytoplasm, and die if one achieves selective killing of the bacteria. ${ }^{210}$ Additional unpublished preliminary results from Doug Green (LIAI, La Jolla, CA, USA) (personal communication) on the mechanisms involved in amoebae/bacteria interaction are consistent with the idea that the bacteria may behave as an addiction module for the single-celled eukaryotes they colonize. If these situations are to be considered as examples of intermediate evolutionary steps towards endosymbiosis, they strongly suggest that the evolution of the present day eukaryote cell may have resulted as much from an initial bacterial manipulation of their host, than from the opposite situation.

In present day mitochondriated eukaryotes, most of the genes encoding mitochondrial proteins are located in the cell nucleus and seem therefore to have been progressively transferred from the mitochondrial genome to the nuclear genome. ${ }^{211}$ In mammalian cells, around a hundred nuclear genes of apparent mitochondrial origin encode around a hundred proteins, that include mitochondrial DNA and RNA polymerases, RNA processing enzymes, ribosomal proteins (reviewed $\mathrm{in}^{204,205}$ ). These proteins are synthesized on cytoplasmic ribosomes, and are then imported into the organelle. Once they have been synthesized and imported into the mitochondria, these proteins are believed never to leave the mitochondria, at least as long as the cell survives. Interestingly, the transfer to the nucleus of the whole mitochondrial genome may have been rendered impossible at some time point by changes in the mitochondrial genetic code that may have prevented the transcription and translation of these mitochondrial genes from the nucleus. Such complex interactions may be better understood if considered in the context of a conflict resulting in an addictive form of enforced endosymbiosis, similar to the addictive enforced endosymbiosis between plasmids and bacteria that I have previously discussed. On the one hand, eukaryotic cells from most organisms are condemned to retain mitochondria, since they have become dependent on aerobic mitochondrial respiratory metabolism; on the other hand, mitochondria cannot leave the cell since most of the proteins that constitute them have become encoded by nuclear genes. Thus the eukaryote cell may be seen as a result of a complex 'evolutionary arms race' between a host and a pathogen, that became somehow frozen, at a given time point, into a state of enforced cooperation whose sole alternative is the self-destruction of the endosymbiont.

The actual outcome of such an ancient evolutionary battle, the present day eukaryote cell, may result from a process of reciprocal addiction between the host and its former pathogen, whereby the survival of the cell depends on the homeostasis and presence of the mitochondria, and the survival of the mitochondria on the homeostasis and presence of the cell. ${ }^{132}$ This evolutionary view provides an interesting framework for considering the findings indicating that an important part of programmed cell death regulation in mammalians occurs at the mitochondria/cytoplasm interface; and that this regulation involves gene products that share some unexpected features with bacterial gene products, such as bacterial toxins.

On the involvement of bacteria-related tools in the control of programmed cell death at the mitochondrial/cytoplasmic interface As previously mentioned, many pro-apoptotic stimuli leading, in mammalian cells, to the executionary phase of programmed cell death seem to require the induction of mitochondrial outer membrane permeabilization that allow the release into the cytosol of proteins that are normally kept sequestered in the mitochondria intermembrane space, such as cytochrome $c$, Smac/Diablo, procaspases, AIF, endonuclease G, and Omi/HtrA2. ${ }^{19,20,81-83,85,212}$ This mitochondrial step seems under the control of the binding to the mitochondrial outermembrane of the Bcl-2 and Bax protein family members that possess a carboxyterminal transmembrane insertion domain.

While the precise binding site of the $\mathrm{Bcl}-2 / \mathrm{Bax}$ proteins on the mitochondrial outer membrane remains controversial, as well as the mechanisms allowing them to regulate outermembrane permeability, ${ }^{82,212}$ the mitochondria appear to be a locus of clustering of several of the main players in the execution and regulation of programmed cell death.

Interestingly, all these players, whether located inside the mitochondria or on its outer surface, are encoded by nuclear genes, and none by mitochondrial genes. This is consistent with previous findings that the mitochondrial DNA contained in the organelle is neither required for the 
induction of the effector phase of programmed cell death, nor for its prevention by the $b c /-2$ gene product, ${ }^{213}$ a finding that was initially interpreted as suggesting the possibility that mitochondria may not be involved in the regulation of programmed cell death.

The genes encoding cytochrome $c$, AIF, endonuclease $\mathrm{G}$, and Omi/HtrA2 (as most genes encoding mitochondrial proteins) are located in the cell nucleus, are highly conserved in eukaryotes, and encode proteins that are synthesized in the cytosol in their precursor form before being exported into the mitochondria. Although now located in the cell nucleus, such genes encoding mitochondrial proteins have homologues in bacteria and are thus presumed to be of ancient bacterial origin. On the other hand, the genes encoding the Bcl-2 family proteins that participate in the suppression of programmed cell death, are presumed to be of eukaryote origin. The determination of the nuclear magnetic resonance and crystal structure of members of the Bcl-2/Bax family that contain a transmembrane pore forming domain, has revealed that these domains are similar to the membrane translocation domain of bacterial toxins ${ }^{214}$ that also form membrane pores and induce membrane depolarization, in particular the colicins and the diphtheria toxin. In other words, the involvement of an organelle of bacterial origin (the mitochondria) in the effector phase of programmed cell death is regulated by a family of genes of apparent eukaryote origin (bcl-2), through three dimensional features that they share with bacterial toxins.

These apparently odd features of programmed cell death regulation may be better understood, as previously mentioned, when replaced in the perspective of an old conflict and an 'evolutionary arms race' between the bacterial ancestor of the mitochondria and the ancestors of the eukaryote cell that led to the emergence of the present day eukaryote cell. ${ }^{132}$ The progressive transfer to the nucleus of the essential mitochondrial genes involved in the regulation of programmed cell death may have represented an important step in the emergence of a regulated participation of the mitochondria in self-destruction. In this context, the mechanisms by which the eukaryote cell induces a mitochondrial membrane permeabilization may be seen as a mechanism by which the eukaryote cell triggers self-destruction through the deletion of an addiction module (the mitochondria), a process that may mimic, and recapitulate, ancient features of the initial proto-eukaryote/proto-bacteria interaction.

The view of mitochondria and the eukaryote cell as 'reciprocal addiction modules' involved in a symbiotic partnership can be integrated in a broad evolutionary continuum that begins with the initial propagation in bacteria of plasmid toxin/antidote modules as addiction modules, prior to the additional functional advantages they may have conferred to the infected cells. This scenario provides a general framework for the evolution of programmed cell death that extends from prokaryotes to single-celled eukaryotes, and from single-celled eukaryotes to the multicellular animals and plants. ${ }^{53,131,132}$ It suggests that a Red Queen hypothesis of prey/predator co-evolution may not only account for the diversification of programmed cell death (as previously discussed), but also for its very origin. This scenario raises additional interesting, yet unanswered questions. For example, some present day single-celled eukaryotes that lack mitochondria, such as the diplomonads, parabasalids, microsporidia, and entamoebae (that include, respectively, the human pathogens Giardia, Trichomonas vaginalis, Encephalis tozoon and Entamoeba histolytica) appear to have lost their endosymbiotic organelle after having transferred several genes of mitochondrial origin to their nuclear genome. ${ }^{169,211}$ Do these single-celled eukaryotes have the capacity to selfdestruct, despite their lack of mitochondria organelles? And, if this is the case, do their nuclear genes of mitochondrial origin play a role in the regulation of programmed cell death? Another question concerns plant cells, that have, in addition to mitochondria, another endosymbiotic organelle of cyanobacterial origin, the chloroplast. Do chloroplasts play a role in the regulation of plant programmed cell death? And since an AP-ATPase, a metacaspase and a TIR domain have been identified in cyanobacteria (as in some other bacterial lineages), ${ }^{92}$ did plants acquire their putative homologues of the apoptotic machinery through this endosymbiotic process?

Whatever the answer may be, an interesting aspect of the multistep scenario outlined above for the evolutionary origin of programmed cell death is the suggestion that the 'altruistic' genetic modules regulating programmed cell death may have initially emerged from the propagation of 'selfish' genetic modules that were selected through their ability to 'addict' the cells that expressed them. It therefore underlines, as previously mentioned, how difficult it can be to address the question of 'why' programmed cell death is present in our cells when considering it solely from the viewpoint of the crucial functional role it now appears to perform in our cells and body.

\section{On self-destruction as an unavoidable consequence of self-organization: the 'original sin' hypothesis}

The scenario that I have outlined above may not be the only possible one for the evolutionary origin of programmed cell death. I have proposed an alternative scenario that has at least three interesting aspects. Firstly, it removes the need to consider that the sole possible effect of an executioner/ antidote module is to induce or repress cell death. Secondly, it removes the need for postulating a multistep process in the emergence and selection of the genetic modules allowing the regulation of self-destruction. Finally, it removes the need to consider that there may have been an initial ancestral period 'before' programmed cell death, during which the cells lacked an intrinsic capacity to self-destruct. It postulates that the origin of the capacity to self-destruct may be as ancient as the origin of the very first cell. ${ }^{53,131,132}$

The hypothesis I have proposed is that effectors of the cell survival (cell cycle and cell differentiation) machinery may have had an intrinsic and ancestral capacity of inducing the self-destruction of the cell in which they operate.

Accordingly, if effectors of the cell survival machinery can also be effectors of the self-destruction of the cell in 
which they operate, then the requirement for coupling cell survival to the prevention of self-destruction may be as old as the origin of the first cell. ${ }^{53,130-132}$

Until now, we have always considered the executioner/ antidote modules as modules whose sole possible effect, in other words whose sole possible 'function', is to induce or repress cell death. We will now abandon any preconceived idea about these executioner/antidote modules. And we will begin by performing a 'Gedanken experiment'.

A 'Gedanken experiment' in the first living cells: on the intrinsic dangers of the molecular processes required for survival Is it possible to envision the molecular pathways and the gene products that participate in cell metabolism, cell cycle or cell differentiation as potential executioners? Let us consider, in a putative ancestor cell of the prokaryotes, the topological manipulations of DNA required for replication, transcription and recombination; the DNA repair mechanisms involved in the correction of DNA damage; the cell membrane repair mechanisms; and the segmentation process of the cell required for cell division; and let us consider in a putative nucleated ancestor of the eukaryotic cell, the processes of rearrangement of chromatin organization, of remodeling or dissolution of the nuclear membrane, and of chromosomal migration required for cell division. And in both prokaryote and eukaryote cells, the regulation of ionic channels, involved in the control of cell metabolism, volume, density and permeability. All cellular processes have intrinsic error rates; and most, if not all, the processes mentioned above involve enzymatic activities that, if not tightly regulated, have the intrinsic potential to lead to cell death. If we attempt to continue this thought experiment in the first living cells, it is tempting to propose that genes encoding molecular tools allowing cell metabolism, differentiation, division and repair could become selected only if they were associated to genes that encoded inhibitors able to control the activity of the former by restricting their error rate.

In mammalian cells, numerous gene products involved in the control of cell cycle and cell differentiation, including protooncogenes, tumor suppressor genes, cyclins, cyclindependent kinases, have also been shown to participate, at various levels, in the regulation of programmed cell death. ${ }^{17,18,20,21,32,122,215,216}$ Such inter-relationships between the regulation of the cell cycle and the regulation of self-destruction are, however, not restricted to cells from multicellular organisms, but also exist in single-celled organisms. Indeed, in yeast, as in mammalian cells, mitotic catastrophes resulting from the uncoordinated activation of cyclins have a phenotype similar, or identical, to apoptosis; ${ }^{217,218}$ in some bacteria species, the autolysins that are required for cell division by breaking the peptidoglycan bacterial wall, can also induce self-destruction in adverse environmental conditions; ${ }^{219}$ and we have seen that the ATP-dependent serine proteases Lon and Clp are involved in both the induction of self-destruction and the regulation of cell cycle in bacteria.

The view I have proposed is that any genetic module that encodes a potent enzyme, that is both vital and dangerous, and its inhibitor represents a potential ancestor of the executioner/antidote modules that may have already operated as regulators of cell death and survival in the first cells. An interesting aspect of this scenario is that it does not postulate the existence of any real evolutionary transition between single-celled organisms unable to undergo regulated self-destruction and single-celled organisms able to achieve programmed cell death. ${ }^{53,131,132}$ Another interesting aspect is that such an evolutionary scenario for the origin of programmed cell death accommodates both the most often proposed phylogenic tree in which prokaryotes are the ancestors of eukaryotes ${ }^{120,169,203,220}$ and one in which both bacteria and eukaryotes diverged from a common extinct ancestor, ${ }^{121}$ or even one in which bacteria emerged from eukaryote ancestors through a process of reductive evolution. ${ }^{221}$

On the evolution of genetic diversification as a model for the evolution of programmed cell death I have argued that in the context of such an hypothesis, the evolution of programmed cell death would share similarities with the evolution of genetic diversification. ${ }^{131}$ The intrinsic inability of a cell to avoid random genetic mutations and alterations has progressively led to the concomitant and apparently antagonistic selection of both the repression of genetic changes, through various mechanisms of DNA proof reading and repair, and the amplification of DNA diversification through various mechanisms of genetic reassortment including recombination, transformation, conjugation, transduction, and finally sexuality. The view that an intrinsic inability to avoid random self-destruction is an 'original sin' of the cell - an inherent consequence of cell metabolism, differentiation, DNA repair, and progression through the cell cycle - implies that evolution has led to the concomitant and apparently antagonistic selection of both the repression and the amplification of the self-destruction machinery. In other words, such a model implies that evolution has led to a continuous fine-tuning of the regulation of self-destruction, rather than to the emergence, at a given time point, of a cell suicide machinery. Such a model provides a simple mechanism for the selection of upstream inhibitors of self-destruction that enhanced the efficiency of cell metabolism, cell cycle, and cell differentiation. At the same time, such a model provides a simple mechanism for the selection of upstream inducers of programmed cell death that allowed enhanced fitness of the colony through the rapid dismissal of altered cells, and provided a selective advantage to the best adapted cells in adverse environmental conditions. Finally, an early coupling of both the DNA damage- and mutation-sensing machinery and the DNA repair and correction machinery to the regulation of programmed cell death may have exerted a potent constraint 'from within' on random genetic drift. Therefore, the evolution of programmed cell death and the evolution of genetic diversification may share more than similarities: they may have deeply influenced each other from the onset, and exerted an important constraint on the process of natural selection. $^{132}$

On the implications of the 'original sin' hypothesis If the capacity to self-destruct represents an unavoidable intrinsic consequence of the capacity to self-organize, a basic property of life, then there may exist as many different pathways 
allowing self-destruction as they are allowing the establishment and maintenance of self-organization. ${ }^{53,132}$ Therefore, the 'original sin' hypothesis implies that there should be no 'bona fide' genetic death program in our cells, whose sole possible effect would be to induce or suppress cell death. Rather, self-destruction would result from various usages of different gene products that each also participates in various pathways involved in cell metabolism, cell differentiation, cell cycle and, more generally, cell survival. ${ }^{53,131,132}$ This hypothesis makes at least two predictions concerning the effectors of self-destruction that operates in our cells. The first prediction is that there should not exist a single family of executionary molecules that is both necessary and sufficient in all instances to induce cell death. The second one is that there should be no effector involved in the execution of cell death that does not also participate in some vital cell function.

Recent findings suggest that these predictions may have some validity. Firstly, several different death 'programs' seem to exist in parallel in our cells, and may operate either together or separately, depending on the circumstances. ${ }^{59,60,222}$ For example, the proteolytic activity of the so called 'executionary' caspases, once believed to be an obligate effector step of programmed cell death, while being important for the induction of the typical phenotypic modifications that characterize apoptosis, is dispensable in several instances for the induction and execution of selfdestruction. ${ }^{59,84,94-100,223}$ In some cases, caspases appear not even to become activated during programmed cell death. ${ }^{59,97}$ Whether such more or less apoptotic, or nonapoptotic, forms of programmed cell death should be designated as caspase-independent cell death, ${ }^{61}$ paraptosis, ${ }^{59}$ or necrosis, ${ }^{100,224}$ has been debated, ${ }^{62}$ but such terminology may still be ambiguous and confusing since both caspase-dependent cell death with non-apoptotic (autophagic) phenotypes ${ }^{225}$ and caspase-independent cell death with apoptotic phenotypes ${ }^{85}$ have been recently reported. Therefore, rather than terminology, the most important point may be the realization, the 'retrorecognition', that there is more than one possible phenotype for programmed cell death, ${ }^{1,2,15,58,60}$ and that this may be due to the existence of several different internally regulated 'programs' of self-destruction. Alternative executionary candidates other than caspases may include members of different proteinase families, ${ }^{226}$ reactive oxygen species, ${ }^{98}$ and mitochondrial proteins such as AIF, endonuclease $G$, and Omi/HtrA2. But, concerning these mitochondrial proteins, it has been recently reported that in some instances, cell death may proceed in the absence of mitochondrial permeabilization. ${ }^{100}$ And in at least one human cell type, the mature erythrocyte, a regulated form of programmed cell death has been reported to occur despite the absence of mitochondria. ${ }^{227,228}$ Thus, there seem to be several different potential executioners, none of which being necessary to cause self-destruction in all circumstances.

The second paradigmatic shift concerns the initial view that the sole possible effect of an 'executioner', once activated, is to induce cell death. Recent reports indicate however that, either the mitochondrial release of AIF into the cytosol ${ }^{229}$ or the proteolytic activation of 'executionary' caspases $^{230}$ can occur without inducing cell death. More importantly, the proteolytic activation of 'executionary' caspases appears, at least in some circumstances, to be required for cell differentiation or cell cycle to proceed, ${ }^{230-236}$ implying that so called 'executioners' of cell death can also participate in vital functions. Thus, after a long quest for the 'obligate' and 'ultimate' executioner of the 'death program', a new and more complex picture is beginning to emerge, suggesting a possible interrelationship and interchange between promiscuous gene products that may participate both in pathways that are required for cell survival, and in pathways that are important for cell death. In this respect, cytochrome $c$, while having never been considered as a 'bona fide' executioner, provides an interesting example of what may be a general rule concerning most, if not all, effectors of cell death: their capacity to behave as actors of either life or death depending on the circumstances. Indeed, when localized inside the mitochondria, cytochrome $c$ plays an important role in cell survival through oxidative phosphorylation, ATP production and energy production. Once released from the mitochondria into the cytosol, however, it participates in the activation of caspases that may result in cell death. Similarly, when localized inside the mitochondria, endonuclease $G$ seems to play an important role in mitochondrial DNA replication, ${ }^{237}$ and once released from the mitochondria, it seems to participate in caspaseindependent cell death. ${ }^{85}$ Also, the cytoplasmic dynaminrelated Drp1 protein, that may participate in the mitochondria fission process that allows mitochondrial replication, has been recently reported to also induce mitochondria fragmentation during programmed cell death induction. ${ }^{238}$

But we might even attempt to go one step further. Is it possible, for example, that the intracytosolic release of mitochondria proteins, such as AIF, when not inducing cell death, ${ }^{229}$ may also participate in some vital cell function, as do activated 'executionary' caspases? As mentioned above, an extreme implication of the view presented here is that there is no such thing as a bona fide genetic 'death program' in our cells. Rather, self-destruction only represents one of the various phenotypes that cells can achieve by using genetic information involved in their 'life program'. While such a view may seem to only raise theoretical questions, it also has obvious therapeutic implications. Firstly, if there are indeed several different self-destruction pathways, the targeting of a given effector for inhibition may not be sufficient to prevent unwanted pathological cell death in all circumstances, and selective, adapted, therapeutic approaches will be required. Secondly, since inhibition of a given effector, when not preventing cell death, may change the death phenotype (from apoptotic to necrotic, for example), such a therapeutic manipulation of the cell death phenotype may either lead to deleterious effects or provide new opportunities concerning the modulation of inflammation, autoimmunity and effector immune responses to infectious or tumor antigens. Finally, if effectors of self-destruction also participate in vital cell functions, the therapeutic activation or inhibition of a given effector may not only influence cell death regulation, but also, depending on the circumstances, cell differentiation 
and cell cycle. I believe that the 'original sin' hypothesis provides a useful conceptual framework for further investigating and addressing this new level of complexity.

The 'original sin' hypothesis and the Caenorhabditis elegans paradigm The nematode Caenorhabditis elegans has provided the paradigm (i) that a single molecular pathway, involving a small number of gene products, is both necessary and sufficient, in all instances, for the induction of cell death, and (ii) that gene products involved in the regulation of programmed cell death have no other possible effect than the induction or repression of programmed cell death. Therefore, it will come as no surprise that the 'original sin' hypothesis appears not to apply to this model organism.

In Caenorhabditis elegans, genetic mutants with a loss of function in the ced-3 gene, encoding the Ced-3 caspase, or in the ced-4 gene, encoding the Ced-4 adaptor protein required for Ced-3 activation, undergo no developmental cell death and are therefore born with 131 additional somatic cells. These additional cells do not show any obvious defect, consistent with the proposal that Ced-3 and Ced-4 have no other effect than inducing cell death. ${ }^{69}$ So, the Caenorhabditis elegans model suggests that the evolution of programmed cell death may have begun, at least in multicellular animals, with the emergence and selection of a unique 'bona fide' genetic death program, that subsequently became linked to other survival programs in animals of more recent phylogenic divergence.

But things may not be so simple, for several reasons. The first one is that it is debated whether Caenorhabditis elegans truly represent an evolutionary simple ancestral metazoan, or rather a stripped down version of an initially more complex multicellular animal ancestor, through a process of reductive evolution leading to secondary simplification. ${ }^{20,92}$ The second reason is that while developmentally regulated apoptotic cell death requires Ced-3 expression, regulated pathological non-developmental, nonapoptotic Ced-3-independent forms of cell death have been described in several $C$. elegans mutants, ${ }^{239-242}$ suggesting the possible existence of alternative executionary pathways. Consistent with these findings, overexpression of CEP-1, the recently identified Caenorhabditis elegans homologue of the mammalian p53 tumor suppressor protein $^{243}$ induces widespread cell death in ced-3 and ced-4 loss of function mutants, implying the existence of a caspase-independent death program. The third reason is that CEP-1, in contrast to Ced-3 and Ced-4, does not seem to solely function as an executioner, but to have several additional properties. Indeed, it may be required for both DNA damage-induced death and normal meiotic chromosome segregation in the germ cells; and also plays a role in the regulation of the whole animal life span in response to environmental stress. ${ }^{243}$ Finally, the last reason is that the genetic control of developmental cell death in Caenorhabditis elegans presents us with an apparent paradox. Caenorhabditis elegans has four genes that have seemingly been selected for only one effect: the control of developmental cell death. But developmental cell death by itself appears to have no function in Caenorhabditis elegans. Indeed, the ced-3 or ced-4 loss-of-function mutants that have 131 additional somatic cells seem to have no significant defects. This may be consistent with the reductive evolution process hypothesis, as mentioned above. Alternately, it is possible that Ced-3- and Ced-4mediated cell death provides some advantages in a wildtype natural environment that are not detected in a laboratory environment. But if this is the case, then it is also possible that additional effects of Ced-3 and Ced-4, unrelated to cell death induction, may also become apparent in a wild-type environment. Finally, different domains of a given protein may be involved in different (pro-death or pro-survival) effects. To come back to the example of the effects of cytochrome $c$ in mammalian cells, the molecular domains that participate in caspase activation are not the same as those ensuring its crucial role in mitochondrial respiratory activity. ${ }^{244}$ Some proteases have been shown to have important functions, such as chaperon-like activity, that do not involve their proteolytic domain and activity, ${ }^{245}$ and recent findings suggest that the presence of a caspase may be required for programmed cell death in some instances, in the very absence of any requirement for caspase proteolytic processing and activation. ${ }^{59}$ Thus, if the Ced-3 protein performs important functions other than the execution of programmed cell death, such additional functions may not obligatorily involve its caspase proteolytic activity. In this respect, as far as I know, all ced-3 loss-of-function mutants in Caenorhabditis elegans studied to date are the consequence of point mutations (and not of gross insertion or deletion processes); therefore, I believe that, in order to assess whether the Ced-3 caspase in Caenorhabditis elegans may have effects other than execution of programmed cell death, that may be independent of their proteolytic activity, it would be important to perform Ced-3 knock-out experiments and to investigate their phenotype. ${ }^{132}$

For all these reasons, I believe it is too early to decide whether the Caenorhabditis elegans model may contradict the 'original sin' hypothesis, may simply represent an exception due to a process of reductive evolution, or may end up being shown as consistent with the hypothesis.

\section{On the synergistic nature of the 'addiction' hypothesis and the 'original sin' hypothesis}

At this stage, I have discussed two different scenarios for the potential origin and evolution of programmed cell death in single-celled organisms: the 'addiction' hypothesis and the 'original sin' hypothesis. But we are not obliged to choose between them. We will now see that these two hypotheses are not antagonistic, but can be seen as complementary and even synergistic. $^{53,132}$

\section{'From killing others to killing self' and 'from killing self to killing others'}

The 'addiction' hypothesis postulates that 'selfish' genetic modules encoding killer genes (toxins) and antagonists of the killer genes (toxin antidotes) have first become selected for the advantage they may have provided the infectious genetic 
modules themselves in terms of propagation, and subsequently for the advantages they provided to the infected cells encoding them in terms of competition with both other infectious agents and other cells. When such 'selfish' genetic modules became integrated in the chromosome of bacteria, they then became selected for the additional evolutionary advantages provided to the colony by their regulated use in self-destruction processes that enhanced the fitness of the colony. In other words, the 'addiction' hypothesis postulates that the ancestors of the executioners involved in programmed cell death were initially involved in 'murder'.

On the other hand, the 'original sin' hypothesis postulates that the ancestors of the genetic modules allowing regulated programmed cell death were already present at the origin of life, and were encoding effectors that allowed functions essential to cell survival as well as repressors that prevented dysregulated activation of these effectors from inducing the stochastic destruction of the cell. An implication of the 'original sin' hypothesis is that these genetic modules allowing both the regulation of vital cellular functions and the regulation of stochastic selfdestruction became subsequently selected in plasmids and viruses as toxin/antidote modules for the 'addictive' advantage they provided these infectious agents. Accordingly, plasmids may have initially acquired their toxin/ antidote addiction module weapons from bacterial chromosomal elements rather than the other way around. An extreme implication of this view is that bacterial antibiotic toxins such as those involved in membrane permeabilization, in DNA fragmentation, or in the modulation of enzyme activity involved in DNA topological changes (such as DNA gyrases) may also exert important vital functions other than killing cells. Whether such toxins may indeed participate (maybe at lower concentrations than those at which they induce killing) in cell signaling, DNA repair, DNA topology, and/or other cell functions is an interesting possibility that deserves investigation.

In such a framework, the frontier between the 'addiction' hypothesis and the 'original sin' hypothesis begins to be blurred, revealing two complementary processes with several shared features able to reinforce each other during evolution. ${ }^{53,132}$ Such a view may become even clearer when we attempt to further consider the respective notions of self-destruction and of murder in the context of the ambiguous and heterogeneous nature of the 'self'.

\section{On the heterogeneous nature of the 'self': enforced cooperation and the evolution towards complexity}

The very notion of the 'self' can be seen as heterogeneous at several levels. A first level of heterogeneity, as we have seen, derives from the moving frontier between infectious 'non-self' genes and the 'self' genome. But there are additional layers of genetic heterogeneity of the 'self' that occur independently of any infectious or horizontal propagation of genes: they are the consequence of genetic mutations. A first level of this heterogeneity can be seen at the level of the cell colony: genetic mutants arise constantly and the mutant genes express themselves on the background of the 'former self' genome. Therefore, at the level of the colony, the 'self' will be constantly redefined as the equilibrium between cells expressing the 'former self' and cells expressing a 'new self'. At the level of each mutant cell itself, the 'self' will also be constantly redefined as the equilibrium between the mutant genes, the 'new self', and the rest of the genome, the 'former self'. But there is another level of heterogeneity. The chromosomal genome is made of a congregation of genes that propagate if, and when, the proteins they encode achieve the minimal degree of cooperation that allows the survival of the cells that harbor them. In principle, the propagation of a given genome results from selective advantages that such a cooperation provides to the cells that harbor it. As we have previously seen, however, 'selfish genes' can be successful at propagating themselves without providing any advantage to the cells that express them, and even more surprisingly, for the paradoxical reason that they can be detrimental to the cells that carry them. ${ }^{179,180,182}$ As we have also seen, genetic modules encoding executioners and protectors may be successful at propagating themselves for the sole reason that they counterselect any cell progeny that will achieve inactivating them. In this context, the destruction of a progeny can be seen either as a process of 'self-destruction' (these genetic modules are part of 'the self' genome) or as murder (these genetic modules are inducing death when the cell has excluded this module from 'the self'). In summary, each cell can be viewed as a heterogeneous environment involving both competition and cooperation between different genetic modules in a given genome; and each colony of single-celled organisms as an environment involving both competition and cooperation between different cells harboring similar or mutant genomes.

In such a 'symbiotic' context of constantly evolving genetic equilibrium, distinctions between the 'self' and the 'non-self', between 'altruism' and 'selfishness', and between 'self-destruction' and 'murder' become difficult to make. ${ }^{53,132}$ In such a context, we begin to perceive that the 'addiction' hypothesis and the 'original sin' hypothesis may represent two different ways to look at a single process. By coupling cell survival to the nature of interactions between different gene products in a given cell, and to the nature of interactions between different cells in a given colony, the modules allowing both regulated selforganization and self-destruction that become selected in prokaryotes and in eukaryotes led to multiple variations on the theme of enforced cooperation. I believe that this is the main reason why the regulation of premature cell death may have represented, since the emergence of the first cell, one of the driving force in the evolution of life towards complexity. And I believe that this is also the main reason for the recent surprising findings that several death 'programs' may exist in parallel in our cells, and that the gene products and molecular pathways that participate in premature cell death may also play a crucial role in cell survival.

Deciphering these ancient and intricate relationships between the regulation of cell survival, cell renewal and cell death, and understanding to what extent these processes may be selectively modulated by therapeutic intervention will probably represent one of the new frontiers of biology and medicine in this century. 


\section{Acknowledgements}

I thank Fabienne Ameisen for the initial suggestion that programmed cell death may have emerged in single-celled organisms; Francoise RussoMarie, for initially pointing out to me that a form of programmed cell death had been described, long ago, in the single-celled eukaryote Dictyostelium discoideum and prokaryote Myxobacteria; Doug Green and Pierre Golstein, for insightful discussions on the hypothesis of the possible origin, existence and role of programmed cell death in evolution and for sharing unpublished results; Pierre Sonigo and Henri Atlan for very stimulating discussions on evolution; and several members of the apoptosis research community, including Andrew Wyllie, Richard Lockshin, Michael Hengartner, Gerry Melino, Martin Raff, Pat Williamson, for stimulating discussions, argumentation and interest in the ideas developed here. The research programs developed in EMI-U 9922 are supported by institutional grants from INSERM and Paris 7 University, and by grants from Agence Nationale de Recherche sur le Sida (ANRS), Ensemble contre le Sida (ECS/Sidaction), Paris 7 University-Valorisation, Fondation pour la Recherche Medicale (FRM) and Etablissement Francais des Greffes.

\section{References}

1. Clarke PG and Clarke S (1996) XIXth century research on naturally occurring cell death and related phenomena. Anat. Embryol. (Berl) 193: 81-99

2. Lockshin RA and ZakeriZ (2001) Programmed cell death and apoptosis: origins of the theory. Nat. Rev. Mol. Cell Biol. 2: 545-550

3. Glucksman A (1951) Cell deaths in normal vertebrate ontogeny. Biol. Rev. Camb. Philos. Soc. 26: 59-86

4. Lockshin RA and Williams CM (1965) Programmed cell death: cytology of degeneration in the intersegmental muscles of the silkmoth. J. Insect Physiol. 11: $123-133$

5. Saunders JWJ (1966) Death in the embryonic systems. Science 154:604-612

6. Tata JR (1966) Requirement for RNA and protein synthesis for induced regression of the tadpole tail in organ culture. Dev. Biol. 13: 77-94

7. Kerr JFR, Willie AH and Currie AR (1972) Apoptosis: a basic biological phenomenon with wide-ranging implications in tissue kinetics. Br. J. Cancer 26 : 239-257

8. HamburgerV, Brunso-Bechtold JKand YipJ(1981)Neuronal death in the spinal ganglia of the chick embryo and its reduction by nerve growth factor. J. Neurosci. 1: $60-71$

9. Umansky S (1982) The genetic program of cell death: hypothesis and some applications: transformation, carcinogenesis, ageing. J. Theor. Biol. 97: 591 602

10. Cowan WM, Fawcett JW, O'Leary DDM and Stanfield BB (1984) Regressive events in neurogenesis. Science 225

11. Duke RC and Cohen JJ (1986) IL-2 addiction: withdrawal of growth factor activates a suicide program in dependent T cells. Lymphokine Res. 5:289-299

12. Ellis HM and Horvitz HR (1986) Genetic control of programmed cell death in the nematode $C$. elegans. Cell 44: 817-829

13. Levi-Montalcini R (1987) Nerve growth factor: 35 years later. Science 237 $1154-1164$

14. Vaux DL, Cory S and Adams JM (1988) bcl-2 gene promotes haematopoietic cell survival and cooperates with c-mycto immortalize pre-B cells. Nature 335 440-442

15. Clarke PG (1990) Developmental cell death: morphological diversity and multiple mechanisms. Anal. Embryol. 181: 195-213

16. Ellis RE, Yuan J and Horvitz HR (1991) Mechanisms and functions of cell death Ann. Rev. Cell. Biol. 7: 663-698

17. RaffMC (1992) Social controls on cell survival and cell death. Nature 356:397400

18. Vaux DL (1993) Towards an understanding of the molecular mechanisms of physiological cell death. Proc. Natl. Acad. Sci. USA 90: 786-789

19. Hengartner $M(2000)$ The biochemistry of apoptosis. Nature 407: 770-776

20. Meier P, Finch A and Evan G (2000) Apoptosis in development. Nature 407: $796-801$
21. Rich T, Allen R and Wyllie A (2000) Defying death after DNA damage. Nature 407: $777-783$

22. Mehmet $\mathrm{H}$ (2000) Caspases find a new place to hide. Nature 403: 29-30

23. Wang JM, Silva JP, Gustafsson CM, Rustin P and Larsson N-G (2001) Increased in vivo apoptosis in cells lacking mitochondrial DNA gene expression. Proc. Natl. Acad. Sci. USA 98: 4038-4043

24. Jacobson MD, Weil M and Raff MC (1997) Programmed cell death in animal development. Cell 88: $347-354$

25. Vaux DL and Korsmeyer J (1999) Cell death in development. Cell 96:245-254

26. Oppenheim RW (1991) Cell death during development of the nervous system. Annu. Rev. Neurosci. 14: 453-501

27. Flanagan JG (1999) Life on the road. Nature 401: 747-748

28. Goldrath A and Bevan M (1999) Selecting and maintaining a diverse T-cell repertoire. Nature 402: 255-262

29. Yuan J and Yankner B (2000) Apoptosis in the nervous system. Nature 407: 802-809

30. Clouston WM and Kerr JFR (1985) Apoptosis, Iymphocytotoxicity and the containment of viral infections. Med. Hypothesis 18: 399-404

31. Cohen JJ (1993) Apoptosis. Immunol. Today 14: 126-130

32. Ameisen JC (1994) Programmed cell death (apoptosis) and cell survival regulation: relevance to AIDS and cancer. AIDS 8: 1197-1213

33. Vaux DL, Haeker G and Strasser A (1994) An evolutionary perspective on apoptosis. Cell 76: $777-779$

34. Williams GT (1994) PCD: a fundamental protective response to pathogens. Trends Microbiol. 12: 463-464

35. Ameisen JC and Capron A (1991) Cell dysfunction and depletion in AIDS: the programmed cell death hypothesis. Immunol. Today 12: 102-105

36. Clem RJ, Fechheimer M and Miller LK (1991) Prevention of apoptosis by a baculovirus gene during infection of insect cells. Science 254: 1388-1390

37. Williams GT (1991) Programmed cell death: apoptosis and oncogenesis. Cell 65: $1097-1098$

38. Yonish-Rouach E, Resnitsky D, Lotem J, Sachs L, Kimchi A and Oren M (1991) Wild-type p53 induces apoptosis of myeloid leukemic cells that is inhibited by IL6. Nature 352: $347-349$

39. Ameisen JC, Estaquier J and Idziorek T (1994) From AIDS to parasite infection pathogen-mediated subversion of programmed cell death as a mechanism for immune dysregulation. Immunol. Rev. 142: 9-51

40. Thompson CB (1995) Apoptosis in the pathogenesis and treatment of disease. Science 267: $1456-1462$

41. Nagata S and Golstein P (1995) The Fas death factor. Science 267: 1449-1456

42. Teodoro JB and Branton PE (1997) Regulation of apoptosis by viral gene products. J. Virol. 71: 1739-1746

43. Zychlinski A and Sansonetti P (1997) Apoptosis as a proinflammatory event: what we can learn from bacteria-induced cell death. Trends Microbiol. 5: 201 204

44. Evan G and Littlewood T (1998) A matter of life and death. Science 281: 1317 1322

45. Krammer $P$ (2000) CD95's deadly mission in the immune system. Nature 407: $789-795$

46. Kerbel R (1997) A cancer therapy resistant to resistance. Nature 390: 335-336

47. Gurney M, Tomasselli A and Heirikson R (2000) Stay the executioner's hand. Science 288: $283-284$

48. Nicholson DW (2000) From bench to clinic with apoptosis based therapeutic agents. Nature 407: 810-816

49. Migliaccio E, Giorgio M, Mele S, Pelicci G, Reboldi P, Pandolfi PP, Lanfrancone $L$ and Pelicci PG (1999) The $p 66^{\text {shc }}$ adaptor protein controls oxidative stress response and life-span in mammals. Nature 402: 309-313

50. Kerr JF (1965) A histochemical study of hypertrophy and ischaemic injury of rat liver with special reference to changes in lysosomes. J. Pathol. Bacteriol. 90 $419-435$

51. Kerr JF (1971) Shrinkage necrosis: a distinct mode of cellular death. J. Pathol. 105: $13-20$

52. Lockshin RA (1997) The early modern period of cell death. Cell Death Differ. 4: $347-351$

53. Ameisen JC (1999) La Sculpture du vivant. Le suicide cellulaire ou la mort créatrice. (2nd edn. 2000). Paris: Editions du Seuil. Al Cuore della vita. (2nd edn. 2001). Milano: Feltrinelli

54. Melino G (2001) Concept: The Sirens' song. Nature 412: 23 
55. Lewontin R (2000) The Triple helix. Gene organism and environment. Cambridge, Ma.: Harvard University Press

56. Savill J and FadokV (2000) Corpse clearance defines the meaning of cell death. Nature 407: $784-788$

57. Green DR and Beere HM (2000) Apoptosis: Gone but not forgotten. Nature 405: $28-29$

58. Schwartz LM, Smith S, Jones MEE and Osborne BA (1993) Do all programmed cell deaths occur via apoptosis? Proc. Natl. Acad. Sci. USA 90: 980-984

59. Sperandio S, deBelle landBredesen D (2000) An alternative non apoptotic form of programmed cell death. Proc. Natl. Acad. Sci. USA 97: 14376-14381

60. Wyllie AH and Golstein P (2001) More than one way to go. Proc. Natl. Acad. Sci. USA 98: $11-13$

61. Samali A, Zhivotovsky B, Jones D, Nagata S and Orrenius S (1999) Apoptosis: cell death defined by caspase activation. Cell Death Differ. 6: 495-496

62. VauxDL (1999) Caspases and apoptosis - biology and terminology. CellDeath Differ. 6: 493-494

63. Steller H (1995) Mechanisms and genes of cellular suicide. Science 267: $1445-1449$

64. Cikala M, Wilm B, Hobmayer E, Bottger A and David CN (1999) Identification of caspases and apoptosis in the simple metazoan Hydra. Curr Biol. 9: 959-962

65. Sulston JE (1976) Post-embryonic development in the ventral cord of Caenorhabditis elegans. Philos. Trans. R. Soc. Lond. B. Biol. Sci. 275: $287-$ 297

66. Sulston JE and Horvitz HR (1977) Post-embryonic cell lineages of the nematode, Caenorhabditis elegans. Dev. Biol. 56: 110-156

67. Hedgecock EM, Sulston JE and Thomson JN (1983) Mutations affecting programmed cell deaths in the nematode Caenorhabditis elegans. Science 220: $1277-1279$

68. Horvitz HR, Sternberg PW, Greenwald IS, Fixsen W and Ellis HM (1983) Mutations that affect neural cell lineages and cell fates during the development of the nematode Caenorhabditis elegans. Cold Spring Harb. Symp. Quant. Biol. $48 \mathrm{Pt}$ 2: $453-463$

69. Horvitz HR (1999) Genetic control of programmed cell death in the nematode Caenorhabditis elegans. Canc. Res. 59 (Suppl): 1701-1706

70. Hoeppner DJ, Hengartner MO and Schnabel R (2001) Engulfment genes cooperate with ced-3 to promote cell death in Caenorhabditis elegans. Nature 412: $202-206$

71. Reddien PW, Cameron S and Horvitz HR (2001) Phagocytosis promotes programmed cell death in C. elegans. Nature 412: 198-202

72. Wiens M, Diehl-Seifert B and Muller WE (2001) Sponge Bcl-2 homologous protein (BHP2-GC) confers distinct stress resistance to human HEK-293 cells. Cell Death Differ. 8: 887-898

73. Inohara N and Nunez G (2000) Genes with homology to mammalian apoptosis regulators identified in zebrafish. Cell Death Differ. 7: 509-510

74. Yuan J, Shaham S, Ledoux S, Ellis HM and Horvitz HR (1993) The C. elegans cell death gene ced-3 encodes a protein similar to mammalian interleukin- $1 \beta$ converting enzyme. Cell 75: 641-652

75. Hengartner MO and Horvitz HR (1994) C. elegans cell survival gene ced-9 encodes a functional homolog of the mammalian proto-oncogene $b c /-2$. Cell 76: $665-676$

76. Vaux DL, Weissman IL and Kim SK (1992) Prevention of programmed cell death in c. elegans by human $b c l-2$. Science 258 : $1955-1957$

77. Finkel $E$ (2001) The mitochondrion: is it central to apoptosis? Science 292 : 624-626

78. Gross A, McDonnell JMand Korsmeyer SJ(1999)Bcl-2 family members and the mitochondria in apoptosis. Genes Dev. 13: 1899-1911

79. Vander Herden M and Thompson C (1999) Bcl-2 proteins: regulators of apoptosis or of mitochondrial homeostasis? Nature Cell. Biol. 1: 209-216

80. Green DR (2000) Apoptotic pathways: Paper wraps stone blunt scissors. Cell 102: $1-4$

81. KroemerG andReed J (2000) Mitochondrial control of cell death. Nature Med. 6: $513-519$

82. Martinou JC and Green D (2001) Breaking the mitochondrial barrier. Nat. Rev. Mol. Cell. Biol. 2: 63-67

83. SuzukiY, Imai Y, Nakayama H, TakahashiK, Takio Kand Takahashi R(2001)A serine protease, $\mathrm{HtrA}$, is released from the mitochondria and interacts with XIAP, inducing cell death. Mol. Cell 8: 613-621
84. Susin SA, Lorenzo HK, Zamzami N, Marzo I, Snow BE, Brothers GM, Mangion J, Jacotot E, Costantini P, Loeffler M, Larochette N, Goodlett DR, Aebersold R, Siderovski DP, Penninger JM and Kroemer G (1999) Molecular characterization of mitochondrial apoptosis-inducing factor. Nature 397: 441-446

85. Li LY, Luo X and Wang X (2001) Endonuclease $G$ is an apoptotic DNase when released from mitochondria. Nature 412: $95-99$

86. Nagata S (2000) Apoptotic DNA fragmentation. Exp. Cell. Res. 256: $12-18$

87. Thornberry NA and Lazebnik Y (1998) Caspases: enemies within. Science281: $1312-1316$

88. Goyal L (2001) Cell death inhibition: keeping caspases in check. Cell 104:805808

89. Li K, Li Y, Shelton JM, Richardson JA, Spencer E, Chen ZJ, Wang X and Williams RS (2000) Cytochrome $c$ deficiency causes embryonic lethality and attenuates stress-induced apoptosis. Cell 101: 389-399

90. Joza N, Susin SA, Daugas E, Stanford WL, Cho SK, Li CY, Sasaki T, Elia AJ, Cheng HY, Ravagnan L, Ferri KF, Zamzami N, Wakeham A, Hakem R, Yoshida $\mathrm{H}$, Kong YY, Mak TW, Zuniga-PfluckerJC, Kroemer G and Penninger JM (2001) Essential role of the mitochondrial apoptosis-inducing factor in programmed cell death. Nature 410: $549-554$

91. Reed J (1999) Splicing and dicing apoptosis genes. Nature Biotechnol. 17: $1064-1065$

92. Aravind L, Dixit VM and Koonin EV (2001) Apoptotic molecular machinery: vastly increased complexity in vertebrates revealed by genome comparisons. Science 291: 1279-1284

93. Speliotes EK, Uren A, Vaux D and Horvitz HR (2000) The survivin-like C. elegans BIR-1 protein acts with the Aurora-like kinase AIR-2 to affect chromosomes and the spindle midzone. Mol. Cell 6:211-223

94. Xiang J, Chao DT and Korsmeyer SJ (1996) Bax-induced cell death may not require ICE-like proteases. Proc. Natl. Acad. Sci. USA 93: 14559-14563

95. McCarthy NJ, Whyte MK, Gilbert CS and Evan GI (1997) Inhibition of Ced-3/ ICE-related proteases does not prevent cell death induced by oncogenes, DNA damage, or the Bcl-2 homologue Bak. J. Cell. Biol. 136: 215-227

96. Deas O, Dumont C, MacFarlane M, Rouleau M, Hebib C, Harper F, Hirsch F, Charpentier B, Cohen GM and Senik A (1998) Caspase-independent cell death induced by anti-CD2 or staurosporine in activated human peripheral $T$ lymphocytes. J. Immunol. 161: 3375-3383

97. Quignon F, De Bels F, Koken M, Feuteun J, Ameisen JC and de Thé H (1998) PML induces a novel caspase-independent death process. Nature Genetics 20: $259-265$

98. Vercammen D, Brouckaert G, Denecker G, Van de Craen M, Declercq W, Fiers $W$ and Vandenabeele $P(1998)$ Dual signaling of the Fas receptor: initiation of both apoptotic and necrotic cell death pathways. J. Exp. Med. 188: 919-930

99. Chautan M, Chazal G, Cecconi F, Gruss P and Golstein P (1999) Interdigital cell death can occur through a necrotic and caspase-independent pathway. Curr. Biol. 9: 967-970

100. Holler N, Zaru R, Micheau O, Thome M, Attinger A, Valitutti S, Bodmer JL, Schneider P, Seed B and Tschopp J (2000) Fas triggers an alternative caspase 8-independent cell death pathway using kinase RIP as effector molecule. Nature Immunology 1: 489-495

101. Parrish J, Li L, Klotz K, Ledwich D, Wang X and Xue D (2001) Mitochondrial endonuclease $\mathrm{G}$ is important for apoptosis in C. elegans. Nature 412: $90-94$

102. Evan GA (1994) Old cells never die, they just apoptose. Trends Cell. Biol. 4: $191-192$

103. Greenberg JT (1996) Programmed cell death: a way of life for plants. Proc. Natl. Acad. Sci. USA 93: 12094-12097

104. Beers EP (1997) Programmed cell death during plant growth and development. Cell Death Differ. 4: 649-661

105. Rubinstein B and Osborne B (1997) Dying for a living: plants do it. Cell Death Differ. 4: 647-648

106. MittlerR(1998)Cell death in plants. In When Cells Die, Lockshin R, ZakeriZand Tilly J, eds. (New York: Wiley-Liss, Inc.) pp. 147-174

107. Greenberg J, Guo A, Klessig D and Ausubel F (1994) Programmed cell death in plants: a pathogen-triggered response activated coordinately with multiple defence functions. Cell 77: 551

108. Levine A, Pennel RI, Alvarez ME, Palmer R and Lamb C (1996) Calciummediated apoptosis in plant hypersensitive disease resistance response. Curr. Biol. 6: 427-437 
109. Solomon M, Belenghi B, Delledonne M, Menachem E and Levine A (1999) The involvement of cysteine proteases and protease inhibitor genes in the regulation of programmed cell death in plants. Plant Cell 11: 431-444

110. DelPoso $O$ and Lam E (1998) Caspases and programmed cell death in the hypersensitive response of plants to pathogens. Curr. Biol. 8: 1129-1132

111. Uren A, O'Rourke K, Aravind L, Pisabarro M, Seshagiri S, Koonin E and Dixit V (2000) Identification of paracaspases and metacaspases: two ancient families of caspase-like proteins, one of which plays a key role in MALT lymphoma. Mol. Cell 6: 961-967

112. Balk J, Leaver CJ and McCabe PF (1999) Translocation of cytochrome c from the mitochondria to the cytosol occurs during heat-induced programmed cell death in cucumber plants. FEBS Lett. 463: 151-154

113. Mitsuhara I, Malik KA, Miura M and Ohashi Y (1999) Animal cell-death suppressors Bcl-XL and Ced-9 inhibit cell death in tobacco plants. Curr. Biol. 9: $775-778$

114. Lacomme $C$ and Santa Cruz S (1999) Bax-induced cell death in tobacco is similar to the hypersensitive response. Proc. Natl. Acad. Sci. USA 96: $7956-$ 7961

115. Clem R and Duckett C (1997) The iap genes: unique arbitrators of cell death. Trends Cell Biol. 7: 337-339

116. Ameisen JC (1998) HIV: Setting death in motion. Nature 395: 117-119

117. Ameisen JC (2001) Apoptosis subversion: HIV-Nef provides both armor and sword. Nat. Med. 7: 1181-1182

118. Freire-de-Lima CG, Nascimento DO, Soares MBP, Bozza PT, Castro-FariaNeto HC, de Mello FG, DosReis GA and Lopes MF (2000) Uptake of apoptotic cells drives the growth of a pathogenic trypanosome in macrophages. Nature 403: $199-203$

119. vanValen $L$ (1973) A new evolutionary law. Evol. Theory I: 1 -30

120. Sogin ML (1991) Early evolution and the origin of eukaryotes. Curr. Op. Gen. Dev. 1: $457-463$

121. Doolittle RF, Feng DF, Tsang S, Cho G and Little E (1996) Determining divergence times of the major kingdoms of living organisms with a protein clock. Science 271: $470-477$

122. Ucker DS (1991) Death by suicide: one way to go in mammalian cellular development? The New Biologist 3: 103-109

123. Dawkins R (1982) The Extended phenotype. Oxford University Press

124. Dawkins R (1986) The Blind watchmaker. Longman

125. Sigmund K (1993) Games of Life. Oxford University Press

126. Oliver Gand Gruss P (1997) Current views on eye development. Trends Neurol. Sci. 9: 415-421

127. Janeway Jr CA and Travers $P(2000)$ Immunobiology. The immune system in health and disease. Curr. Biol.

128. Agrawal A, Eastman Q and Schatz D (1998) Transposition-mediated by RAG1 and RAG2 and its implications for the evolution of the immune system. Nature 394: $744-751$

129. Plasterk R (1998) V(D)J recombination: ragtime jumping. Nature 394: $718-$ 719

130. Ameisen JC, Idziorek T, Billaut-Mulot O, Loyens M, Tissier JP, Potentier A and Ouaissi MA (1995) Apoptosis in a unicellular eukaryote (Trypanosoma cruzi): implications for the evolutionary origin and role of programmed cell death in the control of cell proliferation, differentiation and survival. Cell Death Differ. 2: 285-300

131. Ameisen JC (1996) The origin of programmed cell death. Science 272: 1278 1279

132. Ameisen JC (1998) The evolutionary origin and role of programmed cell death in single celled organisms: a new view of executioners, mitochondria, hostpathogen interactions, and the role of death in the process of natural selection. In When cells die, Lockshin R, Zakeri Z and Tilly J, eds. (New York: Wiley-Liss, Inc.) pp. 3-56

133. Piacenza L, Peluffo G and Radi R (2001) L-arginine-dependent suppression of apoptosis in Trypanosoma cruzi: contribution of the nitric oxide and polyamine pathways. Proc. Natl. Acad. Sci. USA 98: 7301-7306

134. Welburn SC, Dale C, Ellis D, Beecroft R and Pearson TW (1996) Apoptosis in procyclic Trypanosoma brucei rhodesiense in vitro. Cell Death Differ. 3: 229 236

135. Ridgley EL, Xiong ZH and Ruben L (1999) Reactive oxygen species activate a $\mathrm{Ca}^{++}$-dependent cell death pathway in the unicellular organism Trypanosoma bruceibrucei. Biochem. J. 340 (Pt 1): 33-40
136. Moreira MEC, DelPortillo HA, Milder RV, Balanco JM and Barcinski MA (1996) Heat shok induction of apoptosis in promastigotes of the unicellular organism Leishmania amazonensis. J. Cell. Physiol. 167: 305-313

137. Das M, Mukherjee SB and Shaha C (2001) Hydrogen peroxide induces apoptosis-like death in Leishmania donovani promastigotes. J. Cell. Sci. 114 $2461-2469$

138. Lee N, Bertholet S, Debrabant A, Muller J, Duncan R and Nakhasi HL (2002) Programmed cell death in the unicellular protozoan parasite Leishmania. Cell Death Differ. 9: 53-64

139. Arnoult D, Akarid K, Grodet A, Petit PX, Estaquier J and Ameisen JC (2002) On the evolution of programmed cell death: apoptosis of the unicellular eukaryote Leishmania major involves cysteine proteinase activation and mitochondrion permeabilization. Cell Death Differ. 9: 65-81

140. Cornillon S, Foa C, Davoust J, Buonavista N, Gross JD and Golstein P (1994) Programmed cell death in Dictyostelium. J. Cell. Sci. 107: 2691-2704

141. Kaiser D (1986) Control of multicellular development: Dictyostelium and Myxococcus. Annu. Rev. Genet. 20: 536-566

142. Christensen ST, Wheatley DN, Rasmussen Ml and Rasmussen L (1995) Mechanisms controlling death, survival and proliferation in a model unicellular eukaryote Tetrahymena thermophila. Cell Death Differ. 2: 301-308

143. Vardi A, Berman-Frank I, Rozenberg T, Hadas O, Kaplan A and Levine A (1999) Programmed cell death of the dinoflagellate Peridinium gatunense is mediated by $\mathrm{CO}_{2}$ limitation and oxidative stress. Curr. Biol. 9: 1061-1064

144. Madeo F, Fröhlich E, Ligr M, Grey M, Sigrist SJ, WolfDH and Fröhlich KU (1999) Oxygen stress: a regulator of apoptosis in yeast. J. Cell. Biol. 145: 757-767

145. Fraser A and James C (1998) Fermenting debate: do yeast undergo apoptosis? Trends Cell. Biol. 8: 219-221

146. Matsuyama S and Reed J (1999) Yeasts as tool for apoptosis research. Curr. Op. Microbiol. 2: 618-623

147. Maslov DA and Simpson L (1995) Evolution of parasitism in kinetoplastid protozoa. Parasitol. Today 11: $30-32$

148. Wittingham WF and Raper KB (1960) Non-viability of stalk cells in Dictyostelium discoideum. Proc. Natl. Acad. Sci. USA 46: 642-649

149. Wildermuth $H$ (1970) Development and organization of the aerial mycelium in Streptomyces coelicolor. J. Gen. Microbiol. 60: 43-50

150. Wireman J and Dworkin M (1975) Morphogenesis and developmental interaction in Myxobacteria. Science 189: 516-523

151. Kalakoutskii LV and Agre NS (1976) Comparative aspects of development and differentiation in actinomycetes. Bacteriol. Rev. 40: 469-524

152. Wireman J and Dworkin M (1977) Developmentally-induced autolysis during fruiting body formation by Myxococcus xanthus. J. Bacteriol. 129: 796-802

153. Kühn TS (1970) The structure of scientific revolutions. (2nd edn.). Chicago: University of Chicago Press

154. Lightman A and Gingerich $O$ (1991) When do anomalies begin? Science 255 : 690-695

155. Kaiser D and Losick R (1993) How and why bacteria talk to each other. Cell 73: 873-885

156. Davis MC, Ward JG, Herrick G and Allis CD (1992) Programmed nuclear death: apoptotic-like degradation of specific nuclei in conjugating Tetrahymena. Dev. Biol. 154: 419-432

157. Counis MF, Chaudun E, Arruti C, Oliver L, Sanwal M, Courtois Y and Torriglia A (1998) Analysis of nuclear degradation during lens cell differentiation. Cell Death Differ. 5: 251-261

158. Olie RA, Durrieu F, Cornillon S, Loughran G, Gross J, Earnshow WC and Golstein $P$ (1998) Apparent caspase independence of programmed cell death in Dictyostelium. Curr. Biol. 8: 955-958

159. Tatischeff I, Petit PX, Grodet A, Tissier JP, Duband-Goulet I and Ameisen JC (2001) Inhibition of multicellular development switches cell death of Dictyostelium discoideum towards mammalian-like unicellular apoptosis. Eur. J. Cell. Biol. 80: 428-441

160. Arnoult D, Tatischeff I, Estaquier J, Girard M, Sureau F, Tissier JP, Grodet A Dellinger M, Traincard F, Kahn A, Ameisen JC and Petit PX (2001) On the evolutionary conservation of the cell death pathway: mitochondrial release of an Apoptosis-Inducing Factor during Dictyostelium discoideum cell death. Mol. Biol. Cell 12: 3016-3300 
161. Hanada M, Aimé-Sempé C, Sato T and Reed JC (1995) Structure-function analysis of Bcl-2 protein. Identification of conserved domains important for homodimerization with Bcl-2 and heterodimerization with Bax. J. Biol. Chem. 270: $11962-11969$

162. Shimizu S, Shinohara Y and Tsujimoto $Y(2000)$ Bax and Bcl-xL independently regulate apoptotic changes of yeast mitochondria that require VDAC but not adenine nucleotide translocator. Oncogene 19: 4309-4318

163. Roucou X, Prescott M, Devenish RJ and Nagley P (2000) A cytochrome c-GFP fusion is not released from mitochondria into the cytoplasm upon expression of Bax in yeast cells. FEBS Lett. 471: 235-239

164. Gross A, Pilcher K, Blachly-Dyson E, Basso E, Jockel J, Bassik MC, Korsmeye SJ and Forte $\mathrm{M}$ (2000) Biochemical and genetic analysis of the mitochondrial response of yeast to Bax and Bcl-xL. Mol. Cell. Biol. 20: 3125-3136

165. James C, Geschmeissner S, Fraser A and Evan G (1997) Ced-4 induces chromatin condensation in $S$. pombe and is inhibited by direct physical association with Ced-9. Curr. Biol. 7: 246-252

166. Goldmacher VS, Bartle LM, Skaletskaya A, Dionne CA, Kedersha NL, Vater CA, Han JW, Lutz RJ, Watanabe S, Cahir McFarland ED, Kieff ED, Mocarski ES and Chittenden T (1999) A cytomegalovirus-encoded mitochondria-localized inhibitor of apoptosis structurally unrelated to Bcl-2. Proc. Natl. Acad. Sci. USA 96: $12536-12541$

167. Lorenzo H, Susin S, Penninger J and Kroemer G (1999) Apoptosis inducing factor (AIF): a phylogenetically old, caspase-independent effector of cell death. Cell Death Differ. 6: 516-524

168. Hengartner M (2001) Apoptosis: DNA destroyers. Nature 412: 27-29

169. Dacks JB and Doolittle WF (2001) Reconstructing/Deconstructing the earliest eukaryotes. How comparative genomics can help. Cell 107: 419-425

170. Jensen RB and Gerdes K (1995) Programmed cell death in bacteria: proteic plasmid stabilization systems. Mol. Microbiol. 17: 205-210

171. Yarmolinsky MB (1995) Programmed cell death in bacterial populations. Science 267: 836-837

172. Franch T and Gerdes K (1996) Programmed cell death in bacteria: translational repression by mRNA end-pairing. Mol. Microbiol. 21: 1049-1060

173. Miguelez EM, Hardisson C and Manzanal MB (1999) Hyphal death during colony development in Streptomyces antibioticus: morphological evidence for the existence of a process of cell deletion in a multicellular prokaryote. J. Cell. Biol. 145: $515-525$

174. Liu J (1994) Microcin B17: post-translational modifications and their biologica implications. Proc. Natl. Acad. Sci. USA 91: 4618-4620

175. Nordström K and Austin SJ (1989) Mechanisms that contribute to the stable segregation of plasmids. Annu. Rev. Genet. 23: 37-69

176. Gerdes K, Rasmunssen PB and Molin S (1986) Unique type of plasmid maintenance function: postsegregational killing of plasmid-free cells. Proc. Natl. Acad. Sci. USA 83: 3116-3120

177. Katayama Y, Gottesman S, Pumphrey J, Rudikkoff S, ClarkWP and Maurizi MR (1988) The two-component, ATP-dependent CIp protease of Escherichia coli. J. Biol. Chem. 263: 15226-15236

178. Snyder L (1995) Phage-exclusion enzymes: a bonanza of biochemical and cell biology reagents? Mol. Microbiol. 15: 415-420

179. Dawkins R (1976) The Selfish gene. (Oxford University Press)

180. Bull JJ, Molineux IJ and Werren JH (1992) Selfish genes. Science 256: 65

181. Hurst LD and Pomiankowski A (1998) Sexual selection: the eyes have it. Nature 391: $223-224$

182. Naito T, Kusano K and Kobayashi I (1995) Selfish behavior of restrictionmodification systems. Science 267: 897-899

183. Aizenman E, Engelberg-Kulka H and Glaser G (1996) An Escherichia coli chromosomal 'addiction module' regulated by 3',5'-bispyrophospate: a model for programmed bacterial cell death. Proc. Natl. Acad. Sci. USA 93: 6059-6063

184. Losick R and Stragier $P$ (1992) Crisscross regulation of cell-type-specific gene expression during development in B. subtilis. Nature 355: 601-604

185. Hengge-Aronis R (1993) Survival of hunger and stress: the role of rpoS in early stationary phase gene regulation in E. coli. Cell 72: 165-168

186. Kaiser D (1996) Bacteria also vote. Science 272: 1598-1599

187. Ohta N and Newton A (1996) Signal transduction in the cell cycle regulation of Caulobacter differentiation. Trends Microbiol. 4:326-332

188. Costerton JW, Stewart PS and Greenberg EP (1999) Bacterial biofilms: a common cause of persistent infections. Science 284: 1318-1322

189. Velicer GJ, Kroos L and Lenski RE (2000) Developmental cheating in the social bacterium Myxococcus xanthus. Nature 404: 598-601
190. Novak J (1996) Programmed cell death (Response). Science 274: 20

191. Ameisen JC (1996) Programmed cell death (Response). Science 274: 20-21

192. Shapiro $L$ (1993) Protein localization and asymmetry in the bacterial cell. Cell 73: 841

193. Errington J (1996) Determination of cell fate in Bacillus subtilis. Trends Genet. 12: $31-34$

194. Arigoni F, Pogliano K, Webb CD, Stragier P and LosickR(1995) Localization of protein implicated in establishment of cell type to sites of asymmetric division. Science 270: 637-640

195. Nugroho FA, Yamamoto H, Kobayashi Y and Sekiguchi J (1999) Characterization of a new sigma-K-dependent peptidoglycan hydrolase gene that plays a role in Bacillus subtilis mother cell lysis. J. Bacteriol. 181: 62306237

196. Kauffman SA (1993) The origins of order. Self-organization and selection in evolution. (Oxford University Press)

197. Kirschner M, Gerhart J and Mitchison T (2000) Molecular 'vitalism'. Cell 100: 79-88

198. Jan $Y$ and Jan $L$ (1998) Asymmetric cell division. Nature 392: $775-778$

199. Amon A (1996) Mother and daughter are doing fine: asymmetric cell division in yeast. Cell 84: $651-654$

200. Söderbom F and Loomis WF (1998) Cell-cell signaling during Dictyostelium development. Trends Microbiol. 6: 402-406

201. Margulis L (1981) Symbiosis in Cell Evolution. (New York: W.H. Freeman)

202. Margulis L and Sagan D (1997) Microcosmos. Four billion years of microbial evolution. (University of California Press.) First published by Summit Books, 1986.

203. Martin W and Müller M (1998) The hydrogen hypothesis for the first eukaryote. Nature 392: $37-41$

204. Alberts B, Bray D, Lewis J, Raff M, Roberts K and Watson JD (1994) Molecular Biology of the Cell. (New York: Garland Publishing, Inc)

205. Lewin B (1997) Genes VI. (Oxford, New York, Tokyo): Oxford University Press, Inc

206. Doolittle W (1998) Eukaryote origins: a paradigm gets shifty. Nature 392: 1516

207. MénardR, Dehio C and SansonettiPJ(1996) Bacterial entry into epithelial cells: the paradigm of Schigella. Trends Microbiol. 4:220-226

208. Rousset F, Bouchon D, Pintureau B, Juchault P and Solignac M (1992) Nucleotide Wolbachia endosymbionts responsible for various alterations of sexuality in arthropods. Proc. R. Soc. Lond. B. Biol. Sci. 250(1328): 91-98

209. Rigaud T and P J (1993) Conflict between feminizing sex ratio distorters and an autosomal masculinizing gene in the terrestrial isopod Armadillidium vulgare Latr. Genetics 133: 247-252

210. Jeon KW and Jeon MS (1976) Endosymbiosis in amoebae: recently established endosymbionts have become required cytoplasmic components. J. Cell. Physiol. 89: 337-344

211. Palmer JD (1997) Organelle genomes: going, going, gone! Science 275: 790 791

212. Zamzami $N$ and Kroemer $\mathrm{G}$ (2001) The mitochondrion in apoptosis: how Pandora's box opens. Nat. Rev. Mol. Cell. Biol. 2: 67-71

213. Jacobson MD, Burne JF, King MP, Miyashita T, Reed JC and Raff MC (1993) $\mathrm{Bcl}-2$ blocks apoptosis in cells lacking mitochondrial DNA. Nature 361: $365-$ 369

214. Muchmore SW, Sattlet M, Liang H, Meadows RP, Harlan JE, Yoon HS, Nettesheim D, Chang BS, Thompson CB, Wong SL, Ng SL and Fesik SW (1996) $\mathrm{X}$-ray and NMR structure of human Bcl-xL, an inhibitor of programmed cell death. Nature 381: $335-341$

215. Harrington EA, Fanidi A and Evan GI (1994) Oncogenes and cell death. Curr. Op. Gen. Dev. 4: 120-129

216. Shi L, Nishioka WK, Th'ng J, Bradbury EM, Litchfield DW and Greenberg AH (1994) Premature p34 ${ }^{\mathrm{cdc} 2}$ activation required for apoptosis. Science 263 : $1143-1145$

217. Lundgren K, Walmorth N, Booker R, Dembski M, Kirschner M and Beach D (1991) mik1 and wee1 cooperate in the inhibitory tyrosine phosphorylation of cdc2. Cell 64: $1111-1122$

218. Heald R, McLoughlin M and McKeon F (1993) Human wee1 maintains mitotic timing by protecting the nucleus from cytoplasmically activated cdc2 kinase. Cell $74: 463-474$ 
219. Oshida $T$, Sugai $M$, Komatsuzawa $H$, Hong $Y M$, Suginaka $H$ and Tomasz $A$ (1995) A Staphylococcus aureus autolysin that has an N-acetylmuramoyl-Lalanine amidase domain and an endo- $\beta-N$-acetylglucosaminidase domain: cloning, sequence analysis, and characterization. Proc. Natl. Acad. Sci. USA 92: $285-289$

220. Knoll AH (1992) The early evolution of eukaryotes: a geological perspective. Science 256: 622-627

221. Forterre $P(1996)$ A hot topic: the origin of hyperthermophiles. Cell $85: 789-792$

222. Golstein $P$ (1998) Cell death in us and others. Science 281: 1283

223. Xue L, Fletcher G and Tolkovsky A (2001) Mitochondria are selectively eliminated from eukaryotic cells after blockade of caspases during apoptosis. Curr. Biol. 11: 361-365

224. Kitanaka $C$ and Kuchino $Y$ (1999) Caspase-independent programmed cell death with necrotic morphology. Cell Death Differ. 6:508-515

225. Lee CY and Baehrecke EH (2001) Steroid regulation of autophagic programmed cell death during development. Development 128: 1443-1455

226. Foghsgaard L, Wissing D, Mauch D, LademannU, Bastholm L, Boes M, Elling F, Leist $M$ and Jaattela M (2001) Cathepsin B acts as a dominant execution protease in tumor cell apoptosis by TNF. J. Cell. Biol. 153: 999-1009

227. Bratosin D, EstaquierJ, PetitF, ArnoultD, Quatannens B, TissierJP, Slomianny C, Sartiaux C, Alonso C, Huart JJ, Montreuil J and Ameisen JC (2001) Programmed cell death in mature erythrocytes: a model for investigating death effector pathways operating in the absence of mitochondria. Cell Death Differ. 8: $1143-1156$

228. Berg CP, Engels IH, Rothbart A, Lauber K, Renz A, Schlosser SF, SchulzeOsthoff $K$ and Wesselborg $S$ (2001) Human mature red blood cells express caspase-3 and caspase-8, but are devoid of mitochondrial regulators of apoptosis. Cell Death Differ. 8: 1197-1206

229. Dumont C, Dürrbach A, Bidère N, Rouleau M, Kroemer G, Bernard G, Hirsch F, Charpentier B, Susin SA and Senik A (2000) Caspase-independent commitment phase to apoptosis in activated blood T lymphocytes: reversibility at low apoptotic insult. Blood 96: 1030-1038

230. Zeuner A, Eramo A, Peschle C and De Maria R (1999) Caspase activation without death. Cell Death Differ. 6: $1075-1080$

231. Alam A, Cohen LY, Aouad S and Sékaly RP (1999) Early activation of caspases during $T$ lymphocyte stimulation results in selective substrate cleavage in nonapoptotic cells. J. Exp. Med. 190: 1879-1890

232. DeMaria R, Zeuner A, Eramo A, Domenichelli C, Bonci D, Grignani F, Srinivasula SM, Alnemri ES, Testa U and Peschle C (1999) Negative regulation of erythropoiesis by caspase-mediated cleavage of GATA-1. Nature 401:489493
233. Elkon K (1999) Caspases: multifunctional proteases. J. Exp. Med. 190: 1725 1727

234. Kennedy NJ, Kataoka T, Tschopp J and Budd RC (1999) Caspase activation is required for T cell proliferation. J. Exp. Med. 190: 1891-1896

235. Los M, Stroh C, Janicke RU, Engels IH and Schulze-Osthoff K (2001) Caspases: more than just killers? Trends Immunol. 22: 31-34

236. Zermati Y, Garrido C, Amsellem S, Fishelson S, Bouscary D, Valensi F, VaretB, Solary $E$ and Hermine $O$ (2001) Caspase activation is required for terminal erythroid differentiation. J. Exp. Med. 193: 247-254

237. Cote J and Ruiz-Carrillo A (1993) Primers for mitochondrial DNA replication generated by endonuclease G. Science 261: 765-769

238. Frank S, Gaume B, Bergmann-Leitner ES, Leitner WW, Robert EG, Catez F, Smith CL and Youle RJ (2001) The role of dynamin-related protein 1, a mediator of mitochondrial fission, in apoptosis. Dev. Cell 1: 515-525

239. Driscoll $M$ and Chalfie $M$ (1991) The mec-4 gene is a member of a family of Caenorhabditis elegans genes that can mutate to induce neuronal degeneration. Nature 349: 588-593

240. Hall DH, Gu G, Garcia-Anoveros J, Gong L, Chalfie M and Driscoll M (1997) Neuropathology of degenerative cell death in Caenorhabditis elegans. J. Neurosci. 17: 1033-1045

241. Korswagen $H C$, vanderLinden $A M$ and Plasterk RH (1998) G protein hyperactivation of the Caenorhabditis elegans adenylyl cyclase SGS-1 induces neuronal degeneration. EMBO J. 17: 5059-5065

242. Xu K, Tavernarakis N and Driscoll M (2001) Necrotic cell death in C. elegans requires the function of calreticulin and regulators of $\mathrm{Ca}^{++}$release from the endoplasmic reticulum. Neuron 31: 957-971

243. Derry WB, Putzke AP and Rothman JH (2001) Caenorhabditis elegans p53: role in apoptosis, meiosis, and stress resistance. Science 294: 591-595

244. Kluck RM, Bossy-Wetzel E, Green DR and Newmeyer D (1997) The release of cytochrome crom mitochondria: a primary site for $\mathrm{Bcl}-2$ regulation of apoptosis. Science 275: $1132-1136$

245. Rep M, vanDijl JM, Suda K, Schatz G, Grivell LA and Suzuki CK (1996) Promotion of mitochondrial membrane complex assembly by a proteolytically inactive yeast Lon. Science 274: 103-106 